\title{
Comparison of AOD, AAOD and column single scattering albedo from AERONET retrievals and in situ profiling measurements
}

\author{
Elisabeth Andrews $^{1}$, John A. Ogren ${ }^{2}$, Stefan Kinne ${ }^{3}$, and Bjorn Samset ${ }^{4}$ \\ ${ }^{1}$ CIRES, University of Colorado, Boulder, CO 80309, USA \\ ${ }^{2}$ NOAA/ESRL/GMD, Boulder, CO 80305, USA \\ ${ }^{3}$ Max Planck Institute for Meteorology, 20146 Hamburg, Germany \\ ${ }^{4}$ Center for International Climate and Environmental Research - Oslo (CICERO), 0349 Oslo, Norway \\ Correspondence to: Elisabeth Andrews (betsy.andrews@ noaa.gov)
}

Received: 14 September 2016 - Discussion started: 20 October 2016

Revised: 10 March 2017 - Accepted: 18 April 2017 - Published: 16 May 2017

\begin{abstract}
Here we present new results comparing aerosol optical depth (AOD), aerosol absorption optical depth (AAOD) and column single scattering albedo (SSA) obtained from in situ vertical profile measurements with AERONET ground-based remote sensing from two rural, continental sites in the US. The profiles are closely matched in time (within $\pm 3 \mathrm{~h}$ ) and space (within $15 \mathrm{~km}$ ) with the AERONET retrievals. We have used Level 1.5 inversion retrievals when there was a valid Level 2 almucantar retrieval in order to be able to compare AAOD and column SSA below AERONET's recommended loading constraint $(\mathrm{AOD}>0.4$ at $440 \mathrm{~nm}$ ). While there is reasonable agreement for the AOD comparisons, the direct comparisons of in situderived to AERONET-retrieved AAOD (or SSA) reveal that AERONET retrievals yield higher aerosol absorption than obtained from the in situ profiles for the low aerosol optical depth conditions prevalent at the two study sites. However, it should be noted that the majority of SSA comparisons for $\mathrm{AOD}_{440}>0.2$ are, nonetheless, within the reported SSA uncertainty bounds. The observation that, relative to in situ measurements, AERONET inversions exhibit increased absorption potential at low AOD values is generally consistent with other published AERONET-in situ comparisons across a range of locations, atmospheric conditions and AOD values. This systematic difference in the comparisons suggests a bias in one or both of the methods, but we cannot assess whether the AERONET retrievals are biased towards high absorption or the in situ measurements are biased low. Based on the discrepancy between the AERONET and in situ values, we conclude that scaling modeled black car-
\end{abstract}

bon concentrations upwards to match AERONET retrievals of AAOD should be approached with caution as it may lead to aerosol absorption overestimates in regions of low AOD. Both AERONET retrievals and in situ measurements suggest there is a systematic relationship between SSA and aerosol amount (AOD or aerosol light scattering) - specifically that SSA decreases at lower aerosol loading. This implies that the fairly common assumption that AERONET SSA values retrieved at high-AOD conditions can be used to obtain AAOD at low-AOD conditions may not be valid.

\section{Introduction}

The amount and location of absorbing aerosol in the atmosphere are critical for understanding climate change (e.g., Hansen et al., 1997; Ramanathan and Carmichael, 2008; Bond et al., 2013; Samset et al., 2013). Ramanathan and Carmichael (2008) note the effects of absorbing aerosol (which they termed black carbon (BC)) on atmospheric heating rates, precipitation and weather patterns. (Note: the terminology used to refer to absorbing aerosol is imprecise (Petzold et al., 2013; Andreae and Gelencsér, 2006) and encompasses the terms describing chemistry, e.g., BC, and terms describing optical effects, e.g., absorption. The measurements reported herein all refer to light absorption.) The vertical distribution of $\mathrm{BC}$ can also influence its effect on climate (e.g., Haywood and Ramaswamy, 1998; Samset et al., 2013; Ramanathan and Carmichael, 2008). Single scattering albedo (SSA) is an indicator of the absorbing nature of the aerosol; 
higher SSA values indicate a more reflective (whiter) aerosol while a more absorbing aerosol will have lower SSA values. SSA is a primary determinant of whether the aerosol will have a warming or cooling effect (e.g., Haywood and Shine, 1995; Hansen et al., 1997; Reid et al., 1998). Uncertainty in the value of SSA due to uncertainties in the amount of absorbing aerosol can even prevent determination of the sign of aerosol forcing on local to regional scales. Bond et al. (2013) assessed $\mathrm{BC}$ as the second-most-important global-average warming species (top-of-atmosphere forcing $+1.1 \mathrm{~W} \mathrm{~m}^{-2}$; $90 \%$ bounds: +0.17 to $+2.1 \mathrm{~W} \mathrm{~m}^{-2}$ ) after $\mathrm{CO}_{2}$ (in Bond et al., 2013, the direct effect of $\mathrm{BC}$ is $0.71 ; 90 \%$ bounds: +0.09 to $1.26 \mathrm{~W} \mathrm{~m}^{-2}$ ).

Currently, the only way vertical profiles of aerosol absorption can be obtained is via airborne in situ measurements. Such flights are expensive and tend to primarily occur during intensive field campaigns, which are usually aimed at studying specific aerosol types (e.g., biomass burning (BB), African dust, urban/industrial pollution). This reliance on short-term campaigns results in profile data sets that are sporadic in both space and time and not necessarily representative of typical conditions. Additional issues with airborne in situ measurements include adjustment of measurements to ambient conditions, particle losses in sample lines and instrument uncertainties. Nonetheless, in situ vertical profiling of absorbing aerosols has provided useful information to modelers trying to understand climate effects, transport and lifetimes of these important atmospheric constituents (e.g., Koch et al., 2009; Schwarz et al., 2010; Skeie et al., 2011).

The limited availability of in situ vertical profile measurements means modelers must rely on globally sparse and/or temporally sporadic airborne measurements to evaluate $\mathrm{BC}$ vertical distributions in their models. Alternatively, the column properties retrieved from AERONET measurements and inversions have been widely used to provide a first constraint on modeled vertical aerosol properties (e.g., Sato et al., 2003; Koch et al., 2009; Bond et al., 2013; He et al., 2014; Wang et al., 2014). Use of the AERONET data as an absorption constraint has suggested upscaling of modeled aerosol absorption optical depth (AAOD) values by a factor of 2-6 depending on location (e.g., Bond et al., 2013), although Wang et al. (2016) showed that better spatial resolution of models and emission inventories can reduce some of the previously observed model-AERONET discrepancies.

Ground-based remote sensing of both direct attenuation and sky radiances permits inversions of atmospheric columnaveraged absorption. By retrieving the complex refractive indices at different solar wavelengths as well as the average aerosol size-distribution, absorption-related properties can be determined (e.g., AAOD, SSA and absorption Ångström exponent (AAE)). The AERONET network has a fairly wide spatial coverage on land, with long data records at many sites (Holben et al., 1998; Dubovik et al., 2000; Dubovik and King, 2000). One obvious limitation of the AERONET inversion retrievals is that the uncertainty of the derived
SSA becomes very large at low values of AOD (Dubovik et al., 2000). To minimize the effects of this uncertainty, the AERONET Level 2 data invalidate all absorption-related values if the AOD at wavelength $440 \mathrm{~nm}\left(\mathrm{AOD}_{440}\right)$ is below 0.4 (Dubovik et al., 2000, 2002; Holben et al., 2006). Unfortunately, this restriction greatly reduces the spatial and temporal coverage of absorption-related data that can be obtained from AERONET. Moreover, by excluding low-AOD cases, the climatological statistics of AAOD derived from the AERONET Level 2 data may be biased high.

Model analysis of global AOD values suggests that $95 \%$ of global $\mathrm{AOD}_{440}$ values are below 0.4 (Fig. 1), while $89 \%$ of the $\mathrm{AOD}_{440}$ values over land are below the 0.4 threshold. Five models in the AeroCom suite (GMI-MERRA-v3, GOCART-v4, LMDZ-INCA, OsloCTM2 and SPRINTARSv385) have reported daily-average values of $\mathrm{AOD}_{440}$ (for the AeroCom Phase II control experiment), which can be used to develop a cumulative frequency distribution of the percent of the Earth's surface and days where a Level 2 AERONET retrieval of AAOD might be possible (ignoring the presence of clouds and absence of sunlight). Figure 1 indicates that, at best, Level 2 AERONET AAOD retrievals might represent $5 \%$ of the days, globally, and less than $11 \%$ of the days over land. In other words, the AOD constraint on Level 2 AERONET almucantar inversion retrievals means these retrievals represent only a small fraction of the Earth's surface and are biased to conditions of high aerosol loading.

The other information that Fig. 1 provides is the fractional contribution of regions with different $\mathrm{AOD}_{440}$ amounts to the total aerosol and the fossil fuel black carbon (BCFF) radiative budget. These values were derived from monthly data from four models in the AeroCom suite. The fractional contribution to the radiative budget can be mathematically described as follows. For each model grid box there are three quantities: (i) the radiative forcing $\left(\mathrm{W} \mathrm{m}^{-2}\right.$ ), (ii) the horizontal area of the box $\left(\mathrm{m}^{2}\right)$ and (iii) the $\mathrm{AOD}_{440}$. The product of the radiative forcing term and area is the perturbation to Earth's radiative budget due to total aerosol (or BCFF) in the box. The sum of this product over all the boxes is the total perturbation. Figure 1 shows the fraction of the radiative budget perturbation as a function of $\mathrm{AOD}_{440}$. It suggests that approximately $75 \%$ of the total aerosol forcing and $83 \%$ of BCFF forcing is due to regions of the globe where $\mathrm{AOD}_{440}<0.4$. This highlights the significant contribution of aerosol in these cleaner areas to the total global radiation budget.

It should be noted that there is significant inter-model variation in the AeroCom cumulative $\mathrm{AOD}_{440}$ and radiative forcing plots shown in Fig. 1. In particular the BCFF cumulative forcing fraction varies with the lifetime of $\mathrm{BC}$ predicted by the models. A long $\mathrm{BC}$ lifetime results in more dilute AOD and $\mathrm{BCFF}$ radiative forcing distributions. Other issues include the fact that global models have limited spatial and temporal resolution and generally simulate less variability in aerosol properties than is observed in measurements. How- 


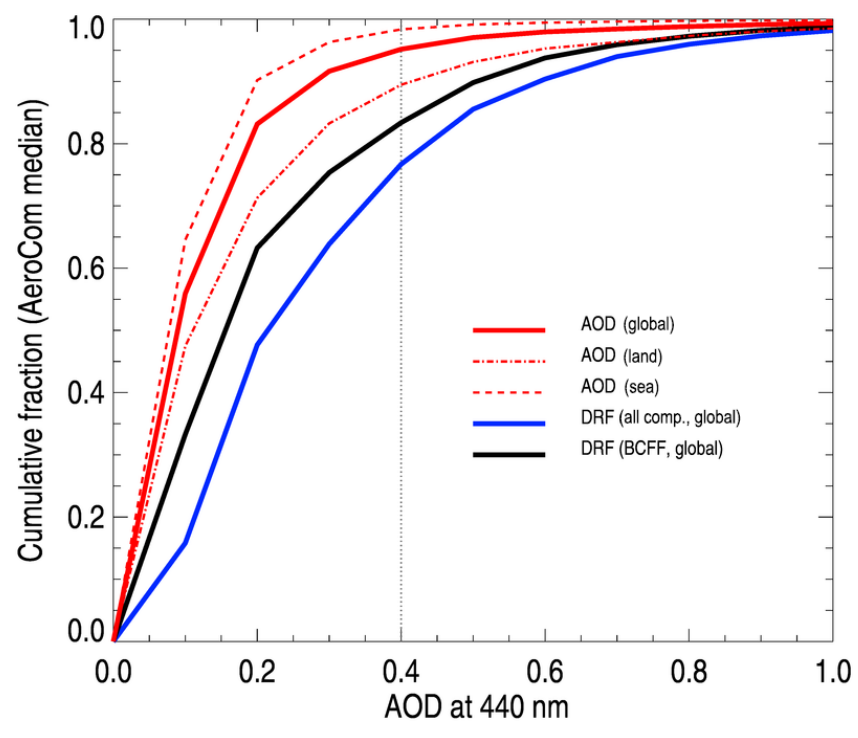

Figure 1. Cumulative $\mathrm{AOD}_{440}$ frequency distribution (red lines) based on output from five AeroCom models. Blue and black lines show contribution of total aerosol and fossil fuel black carbon, respectively, to the global radiation budget as a function of $\mathrm{AOD}_{440}$. See text for details. Models used to generate the AOD lines include GMI-MERRA-v3, GOCART-v4, LMDZ-INCA, OsloCTM2 and SPRINTARS-v385. Models used to generate the radiative forcing lines include all but the GMI-MERRA-v3 model. Model information and references can be found in Myhre et al. (2013).

ever, all models used to generate Fig. 1 follow the same general trend as is shown in Fig. 1, with the take-away point being that $\mathrm{AOD}_{440}$ values $>0.4$ are a relatively rare occurrence.

Because of the potential of the AERONET absorptionrelated retrievals (e.g., AAOD and SSA) for understanding global distributions of absorbing aerosol, there have been many studies comparing AERONET retrieval values with those obtained from in situ measurements in order to assess the AERONET retrieval validity. Such comparisons have taken several different forms. There have been direct comparisons where column SSA or AAOD values calculated from individual in situ vertical profiles have been compared with AERONET-retrieved values for retrievals close in time and space (Haywood et al., 2003; Magi et al., 2005; Mallet et al., 2005; Leahy et al., 2007; Corrigan et al., 2008; Osborne et al., 2008; Johnson et al., 2009; Esteve et al., 2012; Schafer et al., 2014). In addition to direct comparisons there have been general, statistical assessments between AERONET and in situ measurements for both SSA and AAOD, including (a) comparing surface in situ measurements with AERONET retrievals (e.g., Dubovik et al., 2002; Doran et al., 2007; Mallet et al., 2008; Corr et al., 2009), (b) comparing in situ SSA (or AAOD) from a few flight segments to the corresponding column SSA (or AAOD) from AERONET (e.g., Kelektsoglou et al., 2012; Müller et al., 2012) and (c) comparing statistical distributions or averages of AERONET retrievals for a given time period with airborne in situ measurements (e.g., Ramanathan et al., 2001; Leahy et al., 2007; Andrews et al., 2011a; Ferrero et al., 2011; Johnson et al., 2011). Many of these statistical comparisons have shown good agreement between the AERONET and in situ values. This increases general confidence in the AERONET retrievals. However, such statistical comparisons are not appropriate for the evaluation of the accuracy of individual retrievals.

The primary scientific question to be addressed in this paper is whether a consistent bias is observed between AAOD and column SSA obtained from in situ profiling flights and AERONET retrievals. The answer to this question may help determine the validity of adjusting model estimates of AAOD to agree with AERONET retrievals (e.g., Sato et al., 2003; Bond et al., 2013). It should be noted that AERONET does not recommend the use of absorption-related parameters (e.g., SSA, AAOD and complex index of refraction) at $\mathrm{AOD}_{440}$ below 0.4. Dubovik et al. (2000) suggest the uncertainty of AERONET SSA values more than doubles for $\mathrm{AOD}_{440}$ less than 0.2.

In what follows, we first evaluate how direct AERONET AAOD retrievals compare with those derived from multiyear, in situ measurements obtained from vertical profiles over two rural continental AERONET sites in the US. Second, we create a summary of all direct AAOD or SSA comparisons between in situ vs. AERONET data previously presented in the literature in order to place our results about AERONET aerosol absorption-related retrievals in a wider context. Finally, we look at the seasonality of in situ, AERONET and modeled (AeroCom) SSA and AAOD values to see if the annual cycles can provide any insight into observed discrepancies in the direct comparisons. Because this study focuses on only two low-AOD sites in the continental US that are unlikely to be generally representative of other low-loading sites around the globe, and because other factors (e.g., Wang et al., 2016) may contribute to reported differences between modeled and AERONET AAOD, we do not attempt to suggest implications for global BC forcing.

\section{Methods}

This study utilizes data from two sites with collocated AERONET measurements and multi-year, in situ aerosol profiling measurements. The two sites are Bondville (BND, $40.05^{\circ} \mathrm{N} 88.37^{\circ} \mathrm{W} ; 230 \mathrm{~m}$ a.s.l.) and Southern Great Plains (SGP, $36.61^{\circ} \mathrm{N} 97.49^{\circ} \mathrm{W} ; 315 \mathrm{~m}$ a.s.l.). Surface in situ measurements and AERONET column measurements have been made at both locations since the mid-1990s (e.g., Delene and Ogren, 2002; Sheridan et al., 2001; Holben et al., 1998). Weekly to twice-weekly flights measuring in situ vertical profiles of aerosol optical properties over these two sites were made for a subset of the years of ground-based observations. At SGP the in situ profile flights were centered over the site's 
central facility where the AERONET sunphotometer is deployed. Due to FAA flight restrictions, the BND in situ profiling flights took place approximately $15 \mathrm{~km}$ to the westnorthwest of the AERONET sunphotometer location at the BND surface site (Sheridan et al., 2012). Additionally, for BND, a low-level flight leg (200 m a.g.l.) was flown directly over the instrumented BND surface site. The flights at both sites were subject to "visual flight regulations", which means they took place during daylight hours and the plane did not fly in clouds.

At BND and SGP, the median $\mathrm{AOD}_{440}$ values are 0.14 and 0.11, respectively (based on all AERONET Level 2 data from the start of AERONET measurements at each site). These median values fall right around the $50 \%$ mark on the AOD cumulative distribution plot (Fig. 1), indicating BND and SGP may be appropriate sites to explore potential discrepancies between AERONET and in situ AAOD and SSA retrievals at lower AOD conditions.

\subsection{In situ}

The in situ aerosol profiles were obtained with dedicated Cessna 206 airplanes flying stair-step profiles one to two times per week over the two sites. Between 2006 and 2009, 365 flights were flown over BND (out of a total of 401 flown in the region; Sheridan et al., 2012), while 171 aerosol profile flights were flown over SGP in the 2005-2007 time period (Andrews et al., 2011a). The profiles consisted of 10 (at BND) or 12 (at SGP) level flight legs between approximately 450 and $4600 \mathrm{~m}$ a.s.l. (corresponding to approximately 150 and $4200 \mathrm{~m}$ a.g.l.). The profiles, which were "stair-step" descents, took approximately $2 \mathrm{~h}$ to complete as the airplane spent set amounts of time at each level $(10 \mathrm{~min} /$ flight level for flight legs above $\sim 1600 \mathrm{~m}$ a.s.l. and $5 \mathrm{~min} /$ flight level for flight legs below that altitude) in order to improve measurement statistics at the typically cleaner higher-altitude flight levels. Airplane speed was approximately $50 \mathrm{~m} \mathrm{~s}^{-1}$, resulting in the $10 \mathrm{~min}$ upper-level legs being approximately $30 \mathrm{~km}$ long and the $5 \mathrm{~min}$ lower-level legs approximately half that $(15 \mathrm{~km})$ length. This flight pattern means the last $30 \mathrm{~min}$ of the profile were typically in the boundary layer for these two sites and encompassed the majority of the aerosol contribution to column aerosol loading. Previous work has shown that the airplane measurements appear to capture the variability in aerosol properties observed by the long-term, continuous measurements at the surface (e.g., Fig. 3 in Andrews et al., 2004)

Descriptions of the flight profiles and aircraft package have been described in detail in other papers (Andrews et al., 2011a; Sheridan et al., 2012) so only a brief description is provided here. The pilot flew within the constraints provided (specifically defined stair-step profile, vary the time of day, cross wind, over the instrumented field site, during daylight and not within clouds) but without day-to-day scheduling input from scientists. Here, we utilize the same
10 flight levels for both profiling sites: 457, 609, 915, 1219 , $1829,2439,3050,3659$ and $4575 \mathrm{~m}$ a.s.l. Of the 365 flights at BND, 253 flights had complete profiles (all flight levels) with valid scattering, absorption and relative humidity data; at SGP, 132 flights out of 171 were complete. Only complete profiles (all 10 flight levels) were used in this analysis. As is obvious from the vertical range of the flight levels, complete in situ profiles do not equate to complete atmospheric profiles - this is discussed more in the in situ uncertainties discussion (Sect. 2.4.1). The number of flights that could be compared with AERONET measurements is significantly less than this, as discussed in Sect. 2.3 where the merging of the AERONET and in situ data sets is described.

The aircraft were equipped with an inlet that sampled particles with aerodynamic diameter $D_{\mathrm{p}}<7 \mu \mathrm{m}$, and losses in downstream sample lines were estimated to reduce the particle diameter for $50 \%$ sampling efficiency to $5 \mu \mathrm{m}$ (Sheridan et al., 2012). Aerosol light absorption $\left(\sigma_{\mathrm{ap}}\right)$ was measured at three wavelengths $(467,530,660 \mathrm{~nm})$ using a Radiance Research Particle/Soot Absorption Photometer (PSAP) and aerosol light scattering $\left(\sigma_{\mathrm{sp}}\right)$ was measured at three similar wavelengths $(450,550,700 \mathrm{~nm})$ using an integrating nephelometer (TSI model 3563). The measurements of absorption and scattering were made at low relative humidity $(\mathrm{RH}<40 \%)$. Absorption data were corrected for scattering artifacts, flow and spot size calibrations, etc., using the Bond et al. (1999) algorithm, with appropriate modifications for wavelength (Ogren, 2010). The Anderson and Ogren (1998) correction for instrument non-idealities was applied to the nephelometer data.

Ambient temperature $\left(T_{\mathrm{amb}}\right)$ and $\mathrm{RH}\left(\mathrm{RH}_{\mathrm{amb}}\right)$ were measured by a sensor (Vaisala, HUMICAP 50Y) mounted on the aircraft fuselage inside a counterflow inlet shroud, and the nephelometer sample pressure was used as a surrogate for ambient pressure. These measurements of ambient meteorological parameters were used to adjust the in situ optical data to ambient conditions in order to compare with the AERONET measurements and retrievals, which are made at ambient conditions. Climatological IMPROVE network surface aerosol chemistry measurements of sulfate and organic carbon (Malm et al., 1994) were utilized to determine a value for the hygroscopic growth parameter " $\gamma$ " for each site based on the Quinn et al. (2005) parameterization, which relates aerosol hygroscopicity to organic mass fraction. For BND $\gamma=0.71 \pm 0.08$, while for SGP $\gamma=0.65 \pm 0.08$. At BND the IMPROVE chemistry measurements are co-located at the profile location, while for SGP the measurements at the IMPROVE Cherokee Nation site (approximately $56 \mathrm{~km}$ southwest of the profile location) were used. This $\gamma$ value was then used in conjunction with the airborne $\mathrm{RH}_{\mathrm{amb}}$ measurements to adjust the in situ scattering profiles for both SGP and BND.

The equation used to adjust the dry, in situ scattering to ambient relative humidity ( $\mathrm{RH}_{\mathrm{amb}}$ ) is a commonly used aerosol hygroscopic growth parameterization (e.g., Kasten, 
1969; Hanel, 1976; Kotchenruther et al., 1999; Carrico et al., 2003; Crumreyrolle et al., 2014):

$\sigma_{\mathrm{sp}}\left(\mathrm{RH}_{\mathrm{amb}}\right) / \sigma_{\mathrm{sp}}\left(\mathrm{RH}_{\mathrm{dry}}\right)=a \times\left(1-\left(\mathrm{RH}_{\mathrm{amb}} / 100\right)\right)^{-\gamma}$,

where $\sigma_{\mathrm{sp}}\left(\mathrm{RH}_{\mathrm{amb}}\right)$ is the aerosol scattering at ambient $\mathrm{RH}$, $\sigma_{\mathrm{sp}}\left(\mathrm{RH}_{\mathrm{dry}}\right)$ is the measured scattering at low $\mathrm{RH}$ and $\gamma$ is the hygroscopic growth parameter derived from the IMPROVE aerosol chemistry. The value of " $a$ " can be determined using $a=\left(1 /\left(1-\mathrm{RH}_{\mathrm{dry}} / 100\right)\right)^{-\gamma}$ (e.g., Crumreyrolle et al., 2014; Quinn et al., 2005). Here we assume $a=0.9$ based on the typical RH values measured inside the nephelometer for both profile locations $\left(\mathrm{BND} \mathrm{RH}_{\mathrm{dry}}=12 \pm 11 \%\right.$; SGP $\left.\mathrm{RH}_{\text {dry }}=14 \pm 10 \%\right) . \mathrm{RH}_{\mathrm{amb}}$ at BND and SGP averaged 47.4 and $38.6 \%$, respectively, over all flight levels and seasons (56 (BND) and $43 \%$ (SGP) below $1500 \mathrm{~m}$ a.s.1.). The 95th percentile $\mathrm{RH}_{\mathrm{amb}}$ values (calculated over all flights and flight levels) were 79.3 and $76.6 \%$ at BND and SGP, respectively. (Note: scattering-weighted column-averaged $\mathrm{RH}$ values were $54 \%$ at BND and $43 \%$ at SGP.) Applying Eq. (1) to the observed $\mathrm{RH}_{\mathrm{amb}}$ and $\sigma_{\mathrm{sp}}\left(\mathrm{RH}_{\mathrm{dry}}\right)$ profiles, the average enhancement of column-average $\sigma_{\mathrm{sp}}$ due to hygroscopic growth was 1.52 and 1.36 at BND and SGP, respectively. The corresponding 95th percentiles of column-averaged enhancement of scattering were 2.06 and 2.10. While Eq. 1 takes into account differences in hygroscopic growth due to $\mathrm{RH}$ for each segment of each flight, it does not account for compositional changes that might affect the scattering enhancement due to hygroscopicity. For aerosol events such as BB and dust episodes with significantly different composition than the "normal" aerosol, we would expect to overpredict the aerosol hygroscopicity relative to the normal aerosol. Sheridan et al. (2001) showed that the SGP surface aerosol had lower hygroscopicity when it was influenced by dust or smoke.

The absorption measurements were adjusted to ambient temperature and pressure but not to ambient RH because the parameterization of the correction and its magnitude are unknown. It is typically assumed that absorbing aerosol is hydrophobic (e.g., Schmid et al., 2003; Reid et al., 2005; Schaefer et al., 2014), i.e., does not take up water. The uncertainties associated with this assumption are discussed in Sect. 2.4.

Both the scattering and absorption in situ measurements were adjusted to the two nominal Level 2 AERONET wavelengths in the mid-visible spectrum (440 and $675 \mathrm{~nm})$. The $440 \mathrm{~nm}$ wavelength is of interest as that is the wavelength for which the AOD constraint for retrieving SSA and, hence, AAOD is given; the $675 \mathrm{~nm}$ wavelength is also presented because it is less sensitive to $\mathrm{NO}_{2}$, organics and dust, which could potentially bias the in situ-AERONET comparison. Also, evaluating data at both wavelengths helps in attributing aerosol absorption to $\mathrm{BC}$ versus dust, since at $675 \mathrm{~nm}$ absorption is almost entirely caused by BC. The measured scattering Ångström exponent was used to adjust the in situ scattering measurements to the AERONET wavelengths. For the in situ aerosol absorption wavelength adjustments we used a constant absorption Ångström exponent of 1.2 to minimize the effects of noise in the measurement. Previous studies have shown that for both BND and SGP the absorption Ångström exponent is $\sim 1.0$ in the boundary layer and 1.5 at higher altitudes (Andrews et al., 2011; Sheridan et al., 2012). Using the incorrect absorption Ångström exponent will have a negligible effect on the resulting absorption value because of the small difference between the measured and target wavelengths; using an absorption Ångström exponent of 1.2 instead of 1.0 will result in a $1 \%$ difference in adjusted wavelength while using an Ångström exponent of 1.2 instead of 1.5 will result in a $2 \%$ difference in adjusted absorption.

Finally, using these in situ values adjusted to AERONET wavelengths and ambient conditions, the flight profile average properties can be determined. Aerosol extinction $\left(\sigma_{e p}=\sigma_{\mathrm{sp}}+\sigma_{\mathrm{ap}}\right)$ was calculated and integrated vertically for the profile to obtain the in situ AOD. The aerosol absorption for each profile was integrated vertically to obtain the in situ AAOD. As described in Andrews et al. (2004), the in situ column SSA (which is compared to the AERONET SSA value in Sect. 3.1) was calculated for each flight level and then extinction-weighted and integrated to determine column SSA. This results in SSA values which are virtually identical to SSA values calculated using $\left.\mathrm{SSA}_{\text {col, insitu }}=\left(\mathrm{AOD}_{\text {insitu }}-\mathrm{AAOD}_{\text {insitu }}\right) / \mathrm{AOD}_{\text {insitu }}\right)$ and effectively gives higher weighting to the SSA values at altitudes that had the highest aerosol concentrations. Details of the procedure for calculating the vertical integral are given in Andrews et al. (2004), although, in this study, the in situ profiles contained two additional high-altitude flight levels (at 3659 and $4575 \mathrm{~m}$ a.s.l.) and the layer at the highest altitude was assumed to extend $457 \mathrm{~m}$ above the measurement altitude. Profile statistics for various parameters including SSA are provided in Andrews et al. (2004, 2011a) and Sheridan et al. (2012). Individual flight profiles for various parameters are available online at http: //www.esrl.noaa.gov/gmd/aero/net/iap/iap_profiles.html (for SGP) and https://www.esrl.noaa.gov/gmd/aero/net/aao/aao_ prof2007.html (for BND).

\subsection{AERONET}

AERONET measurements have been made at BND since mid-1995 and at SGP since mid-1994. The AERONET network makes spectral measurements of aerosol optical depth (AOD) using CIMEL sun-sky radiometers (Holben et al., 1998). The measurements are typically made at seven wavelengths, with an eighth wavelength used for water vapor measurements. The AERONET website (http://aeronet.gsfc.nasa. gov) provides links to data from more than 500 sites across the globe. The column extinction Ångström exponent $(\AA)$ can be directly calculated from the wavelength-dependent AOD measurements (Eck et al., 1999). In addition to AOD and $\AA$, algorithms have been developed utilizing both the spectral AOD and the spectral angular distribution of the 

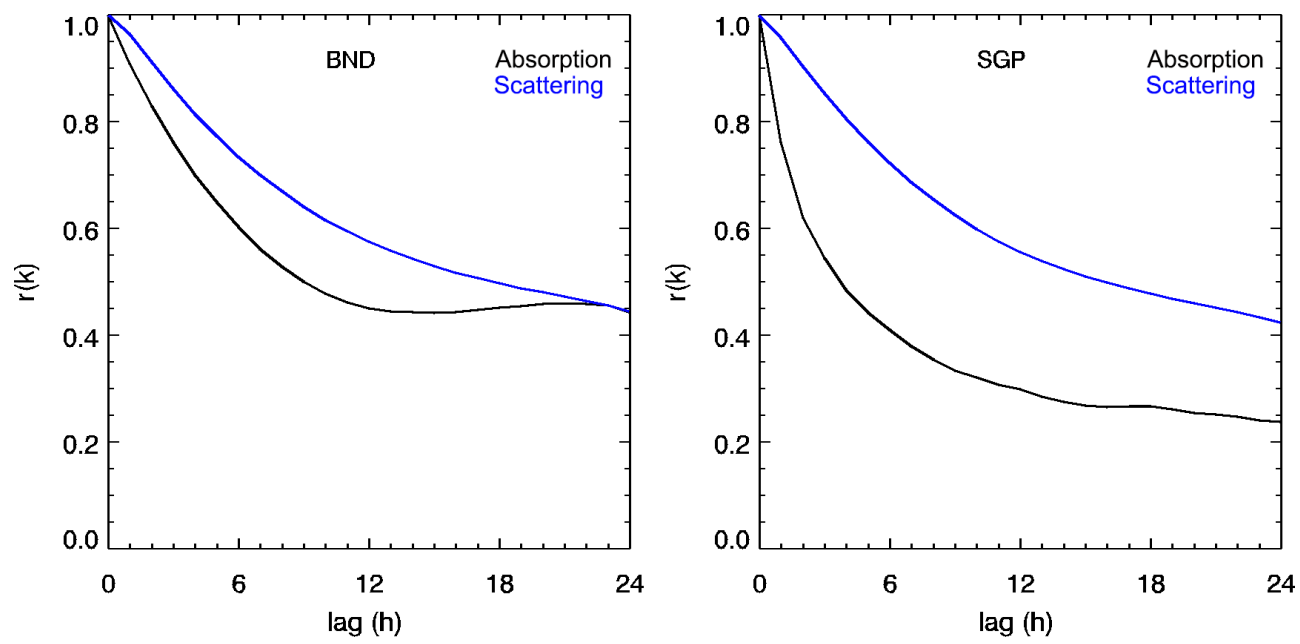

Figure 2. Correlograms for BND and SGP; wavelength $=550 \mathrm{~nm}, D_{\mathrm{p}}<10 \mu \mathrm{m}$, based on hourly averaged surface in situ data between $1995-$ 2013 (BND) and 1996-2013 (SGP). The value $r(k)$ on the $y$ axis represents the autocorrelation at lag time " $k$ ".

sky radiances obtained from almucantar scans, which enable retrieval of other column aerosol properties including AAOD, SSA, size distribution, complex refractive index and fine-mode fraction of extinction $\left(\mathrm{FMF}_{\mathrm{e}}\right)$ (Dubovik and King, 2000; Dubovik et al., 2000, 2006; O’Neill et al., 2003). The nominal wavelengths of the almucantar inversion retrievals are $440,675,870$ and $1020 \mathrm{~nm}$. An additional advantage of the AERONET database is that the retrieval values are obtained consistently - the calibrations, corrections, quality control and algorithms are applied identically for each AERONET location.

For Version 2 AERONET data, there are different levels of AERONET data available for download from the AERONET website. Level 1.0 is unscreened data while Level 1.5 undergoes automated cloud-screening (Smirnov et al., 2000). Level 2 represents data with pre-field and post-field calibrations applied, manual inspection and quality assurance (Smirnov et al., 2000). In addition to the Level 1.5 screening, the criteria for Level 2 almucantar inversion products include a check of the sky residual error as a function of $\mathrm{AOD}_{440}$, solar zenith angle greater than or equal to $50^{\circ}$ and almucantars with a minimum number of measurements in each of the four designated scattering angle bins. Further, for Level 2 absorption-related products (including SSA, AAOD, $\mathrm{AAE}$ and the complex refractive index) the $\mathrm{AOD}_{440}$ must be greater than 0.4 to exclude more uncertain aerosol absorption estimates (Holben et al., 2006). Version 3 AOD products are now available but the Version 3 inversion products were not at the time of this writing.

The AAOD values reported in the AERONET almucantar inversion files are obtained using the relationship AAOD $=(1-$ SSA $) \times$ AOD. Schafer et al. (2014) have a nice description of how SSA is obtained from the AERONET measurements. In the present study, in order to maximize the number of AERONET data points available for comparison with the in situ measurements, Level 1.5 retrievals of AAOD and SSA were included in the analysis if there was a corresponding valid Level $2 \mathrm{AOD}$ value but $\mathrm{AOD}_{440}<0.4$ (i.e., the same primary criterion as was used in Bond et al., 2013). We will refer to these AAOD and SSA values as $1.5^{*}$ data.

\subsection{Merging the in situ and AERONET data sets}

Merging of collocated (within $15 \mathrm{~km}$ ) but temporally disparate data sets can induce discrepancies in the combined data set. Lag-autocorrelation analysis (e.g., Anderson et al., 2003 ) is used to determine an appropriate time window for comparison of the AERONET and in situ profile measurements. Figure 2 shows that, at the surface, at both BND and SGP, scattering is well correlated $(r(k)>0.8)$ out to $4-5 \mathrm{~h} \mathrm{lag}$, while absorption is less correlated than scattering $(r(k)$ for absorption is 0.75 at BND and 0.55 at SGP). Based on the correlograms, AERONET retrievals were merged with the in situ profile data when the retrievals were within $\pm 3 \mathrm{~h}$ of the end of the in situ profile. This is the same time range constraint used to compare AERONET and PARASOL SSA values (Lacagnina et al., 2015). Additionally, Fig. 2 represents the maximum correlation that we can realistically expect to achieve in a comparison of two different instruments with temporally offset measurements and provides context for the AERONET-in situ comparisons presented in Sect. 3.

Because the profiles are "stair-step" descents from $\sim 4600 \mathrm{~m}$ a.s.l. down to $\sim 450 \mathrm{~m}$ a.s.l. (e.g., see Fig. 4 in Sheridan et al., 2012), matching with AERONET retrievals at the end of the profile means that the matches are more closely aligned with when the airplane is in the boundary layer and thus, typically, sampling the highest aerosol concentrations. This way the maximum time difference between the boundary layer portion of the flight and the AERONET retrieval is $3 \mathrm{~h}$; if we had chosen to match based on the start of the flight, 


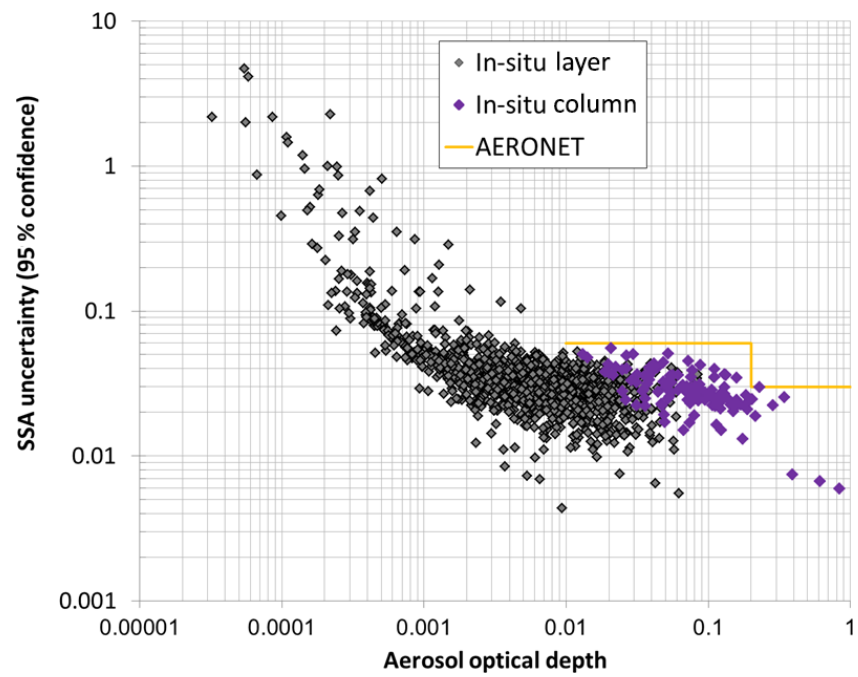

Figure 3. SSA uncertainty as a function of aerosol optical depth. Black points represent the SSA uncertainty (95\% confidence) in each flight layer (all three visible wavelengths measured by the PSAP and nephelometer) as a function of the AOD of that flight layer. Purple points represent the in situ column SSA uncertainty for each flight (again points include all three wavelengths measured by the PSAP and nephelometer) as a function of the in situ AOD. Orange line represents the uncertainty in SSA reported by Dubovik et al. (2000, their Table 2) for two AOD ranges.

the maximum time difference between the boundary layer measurements and the AERONET retrieval would have been as large as $5 \mathrm{~h}$. The boundary layer portion $(<1800 \mathrm{~m}$ a.s.l. $)$ of the $\sim 2 \mathrm{~h}$ profile takes approximately $30 \mathrm{~min}$. While the $\pm 3 \mathrm{~h}$ match window was chosen based on the surface in situ aerosol lag-autocorrelation statistics (Fig. 2), other time windows were also examined. For time windows less than $\pm 3 \mathrm{~h}$ (e.g., 1 and $2 \mathrm{~h}$ ) the fit coefficients (slope, intercept) did not change significantly although the AOD and AAOD correlation coefficients did improve for those smaller time windows. For time windows longer than $\pm 3 \mathrm{~h}$ (e.g., 6 and $12 \mathrm{~h}$ ) there were changes in AOD and AAOD fit parameters and the correlation coefficients decreased significantly. For SSA there appeared to be no correlation between AERONET retrievals and in situ calculated values regardless of match window length (highest SSA correlation coefficient was 0.12 , but most were less than 0.05 for both sites). The poor correlations for SSA are not surprising given the uncertainties at low loading. The AERONET-in situ comparisons for the $\pm 3 \mathrm{~h}$ window are discussed in Sect. 3.1 below.

\subsection{Uncertainties in in situ and AERONET data}

In any study comparing parameters obtained from different instruments and/or methods, an understanding of the uncertainties in each of the parameters being compared is critical. Below we discuss the uncertainties inherent in both the in situ and AERONET data sets.

\subsubsection{In situ uncertainties}

Uncertainties for measurements by the in situ instruments have been described previously (e.g., Sheridan et al., 2002; Formenti et al., 2002; Shinozuka et al., 2011; Sherman et al., 2015) so only an overview is provided here. Sheridan et al. (2002) calculated uncertainties in aerosol light scattering for the TSI nephelometer to be $7-13 \%$ for $10 \mathrm{~min}$ legs depending on amount of aerosol present - the higher uncertainty value applies to very low aerosol loadings (scattering $<1 \mathrm{Mm}^{-1}$ ). We assume that uncertainty in the profile scattering measurements is $13 \% ; 13 \%$ is appropriate for the higher-altitude flight legs (10 min duration with, typically, low aerosol loading) and is also reasonable for the loweraltitude flight legs which are only $5 \mathrm{~min}$ in duration but have significantly higher loading. At both BND and SGP the median boundary layer scattering is typically $>10 \mathrm{Mm}^{-1}$, while median scattering for the upper-altitude flight legs is typically between 1 and $10 \mathrm{Mm}^{-1}$ (Andrews et al., 2011; Sheridan et al., 2012).

Unfortunately, because profile-specific aerosol hygroscopicity measurements were not available for the in situ aircraft measurements described here, a single hygroscopic growth parameterization was applied for all profiles at each site as described in Sect. 2.1 and Eq. (1). To determine the uncertainty in AOD induced by the uncertainty in the scattering adjustment to ambient RH, AOD values were calculated using different $\gamma$ values representing the range of hygroscopic growth factors suggested by the aerosol chemistry. Specifically, $\mathrm{AOD}_{440}$ was calculated for $\gamma+1$ standard deviation and $\gamma+2$ standard deviations. As described above, $\gamma$ was calculated from the climatological chemistry measurements made by the IMPROVE network (14 years of data, $\sim 1700$ data points at BND; 10 years of data, $\sim 1000$ data points at SGP) using the Quinn et al. (2005) parameterization. We calculated the mean and standard deviation of $\gamma$ based on those climatological chemistry measurements. Using this approach, the uncertainty in AOD due to adjustment to ambient RH was determined to be between 9 and $16 \%$. This uncertainty might seem to be low, but the 95th percentiles of ambient $\mathrm{RH}$ values observed throughout the profiles were $\sim 80 \%$ but more typically ambient RH in the boundary layer was less than $70 \%$ at BND and less than $60 \%$ at SGP. Sum-ofsquares uncertainty analysis suggests the overall uncertainty in the in situ AOD is approximately $30 \%$ for higher ambient humidities $\left(\mathrm{RH}_{\mathrm{amb}}>70 \%\right)$ and approximately half that at $\mathrm{RH}_{\mathrm{amb}}<50 \%$.

Both Jeong and Li (2010) and Eck et al. (2014) have noted that the presence of nearby clouds may influence AOD values. They investigated the effect of high RH halos embedded in aerosol layers that typically exist in the vicinity of non-precipitating cumulus clouds. If the AERONET retrieval went through such a halo it could result in an increased AOD due to the combined effects of hygroscopic growth, cloud processing of aerosols and rapid gas-to-particle conversions. 

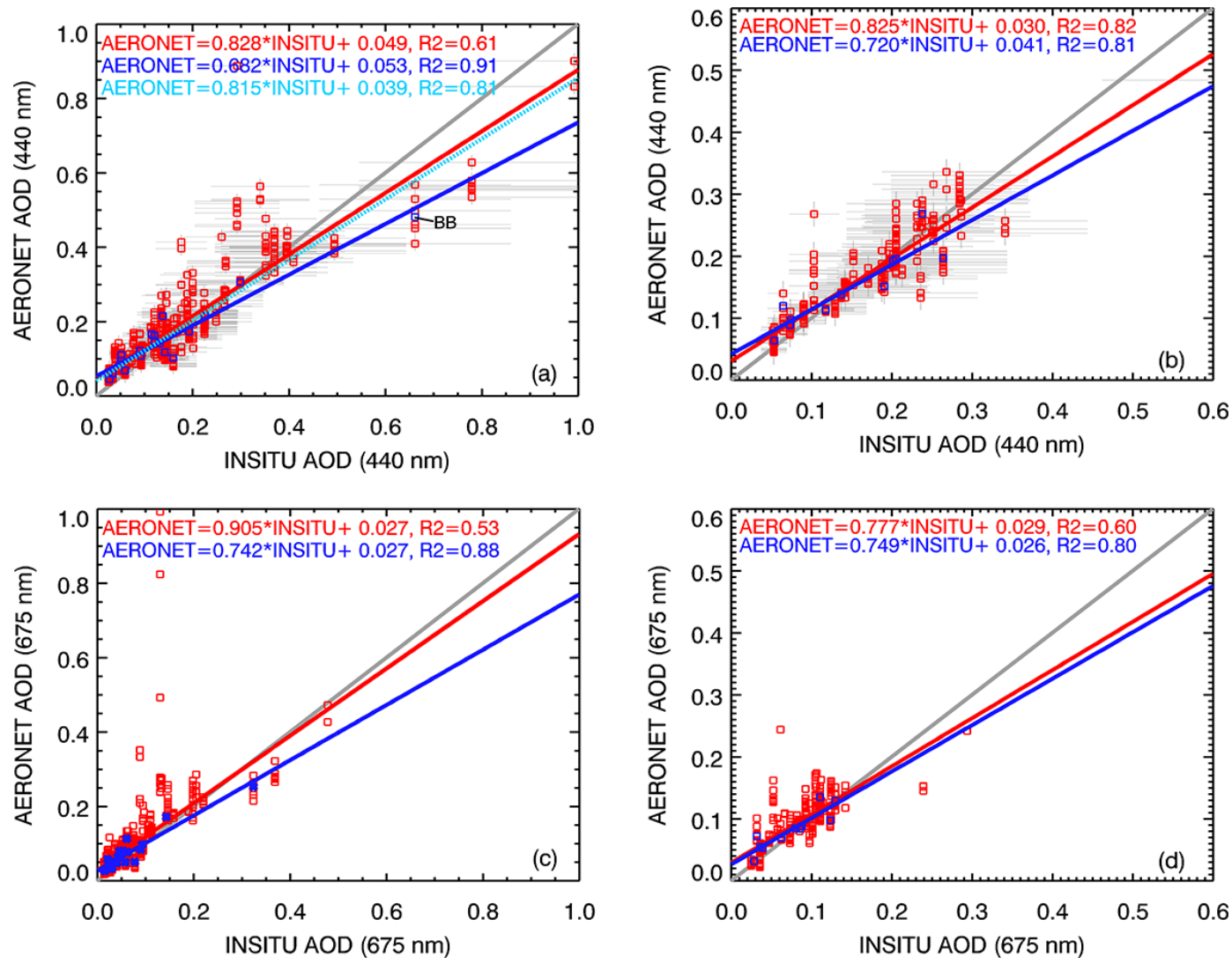

Figure 4. AOD comparison (a) BND at $440 \mathrm{~nm}$, (b) SGP at $440 \mathrm{~nm}$, (c) BND at $675 \mathrm{~nm}$ and (d) SGP at $675 \mathrm{~nm}$; thick gray line is 1 -to-1 line. Thin gray lines associated with each data point represent measurement uncertainties. Red points and fit line represent all AERONET direct-sun Level 2 AOD measurements within $\pm 3 \mathrm{~h}$ of the end of the profile. Blue points and fit line represent the average of AERONET Level 2 AOD measurements with successful almucantar retrievals within $\pm 3 \mathrm{~h}$ of the end of the profile. The light blue dashed line is the fit when the BB point is excluded. Note: two BND direct-sun AOD440 points corresponding to the two highest AOD675 points in (c) are off the scale of the plot and not shown. The third high AOD440 point is partly obscured by the legend.

If the aircraft also flew through this RH halo then the effect would also be accounted for in the RH-corrected in situ measurements. However, if the high RH layer was between two flight levels then the aircraft measurements would not account for it. Addressing this effect is outside the scope of this paper.

The PSAP measurement of aerosol absorption is more uncertain than the aerosol scattering measurements - PSAP uncertainty is reported to be in the $20-30 \%$ range (e.g., Bond et al., 1999; Sheridan et al., 2002; Sherman et al., 2015). It should be noted that the PSAP absorption measurement represents all absorbing aerosol collected on its filter, as opposed to being specific to $\mathrm{BC}$ absorption. That is actually helpful for this particular study as the AERONET retrieval of AAOD also represents all flavors of absorption (e.g., BC, "brown carbon" and dust). Müller et al. (2011) describe detailed experiments to characterize filter-based absorption instruments and describe some additional limitations of the instruments.

There is, however, some question of whether the PSAP (or any filter-based measurement) is able to accurately represent absorption by particles coated with semivolatile or liquid organics due to the possibility of such coatings changing the characteristics of the filter substrate (oozing!) after impaction (e.g., Subramanian et el., 2007; Lack et al., 2008). Comparisons of filter-based absorption measurements for denuded and un-denuded particles (e.g., Kanaya et al., 2013; Sinha et al., in revisions, 2017) suggest that the un-denuded particles have absorption enhancements of 5-25\% relative to those that have been through a denuder. These comparisons show that stripping off coatings and evaporating the non-absorbing particles reduces the measured absorption, i.e., that the effect of coatings is not completely lost in filter-based measurements. The effect of coatings appears to increase the absorption value reported by the PSAP relative to that reported by a non-filter-based instrument (Lack et al., 2008); in other words the aerosol absorption values obtained from PSAP measurements may have a positive bias. It is worthwhile to explore the potential magnitude of such a bias. The mean mass concentrations of organic aerosol determined from the IMPROVE measurements near BND and SGP (the OCf value 
in the IMPROVE data set; Malm et al., 1994) are similar for both sites and less than $2 \mu \mathrm{g} \mathrm{m}^{-3}$, putting them firmly in the rural/remote category identified by Lack et al. (2008; their Fig. 4). Depending on whether Fig. 3 or Fig. 4 in Lack et al. (2008) is used, the results of Lack et al. (2008) suggest that the PSAP might be overestimating absorption by a factor of 1.1-1.5 due to artifacts caused by organic aerosols. However, in a subsequent study, Lack et al. (2012) reported a PSAP overestimate by factors of 1.02-1.06 over Los Angeles, considerably lower then the Lack et al. (2008) results.

The positive bias in absorption related to filter-based measurements is the same order of magnitude and direction of the absorption enhancement factor found by some lab and theoretical studies for coated absorbing particles suspended in the atmosphere. Absorption enhancement values of 1.3-3 have been predicted for coated particles (e.g., Bond et al., 2006; Lack et al., 2009; Cappa et al., 2012) although enhancements larger than a factor of 2 have not been measured for ambient aerosol (e.g., Lack et al., 2008; Cappa et al., 2012; McMeeking et al., 2014). Wang et al. (2014) suggested that an absorption enhancement factor of 1.1 was appropriate for fossil fuel influenced aerosol and that 1.5 was a more reasonable enhancement factor for biomass-burning-affected aerosol. Biomass burning does not have a consistent influence on either BND or SGP. Cappa et al. (2012) suggested that the discrepancies between ambient and modeled and/or laboratory results could be a result of differences in particle morphology and/or chemistry. We have not made any adjustments for the absorption effects of coatings or the potential positive bias in PSAP measurements as the science is still unclear.

In addition to the potential absorption enhancement due to organic coatings, it has been suggested that aerosol water on absorbing particles may also enhance absorption. There have been very few studies where the hygroscopic growth enhancement of absorption was explicitly considered. Redemann et al. (2001) modeled absorption enhancement as a function of RH based on characteristic atmospheric particles and found absorption enhancement values of up to 1.35 at $95 \% \mathrm{RH}$; for the 95th percentile $\mathrm{RH}_{\mathrm{amb}}$ values encountered at BND (78.9\%) and SGP (76.6\%), the Redemann et al. (2001, their Fig. 2) study would suggest absorption enhancements of $\sim 1.1$. Nessler et al. (2005) and Adam et al. (2012) utilized both ambient aerosol measurements and Mie theory to calculate absorption enhancement values due to hygroscopic water uptake. Nessler et al. (2005) do not provide absorption enhancements as a function of $\mathrm{RH}$, but Adam et al. (2012) suggest absorption enhancements due to hygroscopic growth of less than 1.1 at $80 \%$ humidity. Brem et al. (2012) report on laboratory studies that show that aerosol absorption was enhanced by a factor of 2.2 to 2.7 at $95 \%$ relative humidity relative to absorption at $32 \%$ relative humidity, although for RH less than $\sim 80 \%$ (i.e., the RH values observed in this study) they show no absorption enhancement (their Fig. 9). Lewis et al. (2009) actually observe a decrease in absorption with increasing RH for some biomass fuels but hypothesize the decrease might have been due to their measurement technique and/or a change in the morphology of the particles.

In summary, the positive bias in the PSAP measurements of aerosol light absorption might be as high as a factor of 1.1 to 1.5 due to oozing (e.g., the overestimate of absorption reported by Lack et al. (2008) for filter-based measurements). Atmospheric absorption may be underestimated by PSAP measurements by up to a factor of 1.5 due to not accounting for coating (organic or water) effects. Without additional laboratory and field measurements to quantify the net effect of the possible positive and negative biases in PSAP measurements of aerosol light absorption, it is not possible to estimate the actual uncertainty in the in situ light absorption measurements reported here due to coating effects. To address this, we double the assumed PSAP uncertainty of $\sim 25$ to $50 \%$ in the calculations of uncertainty.

One aspect of the in situ system that will affect both the scattering and absorption measurement is the gentle heating used to dry the particle to $\mathrm{RH}<40 \%$. The drying process we use (heating of $40^{\circ} \mathrm{C}$ or less) may remove some volatile components but we believe the removal to be minimal $(<10-20 \%)$ based on lab and ambient volatility studies in the literature. Thermal denuder studies suggest little removal of volatile components $(<10 \%)$ at $40^{\circ} \mathrm{C}$ (e.g., Mendes et al., 2016; Huffman et al., 2009; Bergin et al., 1997) although thermal denuders results may be limited by short residence times $(<20 \mathrm{~s})$. However, smog chamber evaporation studies on ambient aerosol over longer time periods (minutes-hours) at ambient temperature also suggest ambient aerosol may be less volatile than previously thought Vaden et al. (2011) showed that ambient secondary organic aerosol lost just $\sim 20 \%$ of its volume after $\sim 4 \mathrm{~h}$.

Once the uncertainties in the in situ aerosol scattering and absorption are known, the uncertainty in SSA (SSA = $\sigma_{\mathrm{sp}} /\left(\sigma_{\mathrm{sp}}+\sigma_{\mathrm{ap}}\right)$ can also be calculated. Formenti et al. (2002, their Eq. 5) suggest the uncertainty in single scattering albedo $(\delta \mathrm{SSA} / \mathrm{SSA})$ can be calculated as follows:

$\left.\delta \mathrm{SSA} / \mathrm{SSA}=(1-\mathrm{SSA}) \times\left[\left(\delta \sigma_{\mathrm{sp}} / \sigma_{\mathrm{sp}}\right)^{2}+\left(\delta \sigma_{\mathrm{ap}} / \sigma_{\mathrm{ap}}\right)^{2}\right)\right]^{1 / 2}$.

As an example, for scattering uncertainties of $30 \%$ (combined nephelometer and $f(\mathrm{RH})$ induced uncertainty), PSAP absorption uncertainties of $50 \%$ and SSA values of 0.95 (typical of the in situ SSA observations), Eq. (2) results in an in situ SSA uncertainty of $\sim 3 \%$ or approximately 0.03 . For the higher-altitude flight segments the loading does tend to be quite a bit lower and thus has higher uncertainty but those upper-level segments contribute little to the overall AOD or AAOD. Because the flight column SSA is calculated using extinction-weighted SSA flight segments, segments with very low aerosol concentrations will have little impact on the column SSA derived from the flight measurements. Figure 3 shows the calculated SSA uncertainties for each flight layer as well for the in situ column SSA for each individual flight. 
For high AOD (AOD $>0.3)$ the SSA uncertainty is quite low (less than 0.01), while for lower loading $(0.005<\mathrm{AOD}<0.2)$ the SSA uncertainty is less than 0.06 (the median uncertainty in this low-AOD range for the in situ flights in this study is $\sim 0.03$ ).

In addition to instrumental uncertainties there are also uncertainties associated with the aircraft flight patterns, i.e., the presence of aerosols below, between and above the discrete flight levels. Missing aerosol above and below an aircraft profile is a potential issue in all aircraft-column comparisons. Different approaches have been used to assess whether aerosol loading contributions above the highest flight level (4.6 km a.s.1.) are important. Andrews et al. (2004) utilized Raman lidar measurements to determine that $80-90 \%$ of the aerosol was below $3.7 \mathrm{~km}$ a.s.l. at SGP $(3.7 \mathrm{~km}$ was the maximum altitude flown by the original SGP airplane, although all the profile flights utilized here occurred after the maximum flight level was increased to $4.6 \mathrm{~km}$ a.s.l.). Andrews et al. (2004) also assumed an AOD contribution of 0.005 from stratospheric aerosol, which was not done here. At SGP, Turner et al. (2001) segregated lidar aerosol extinction profiles by season and AOD. Their results (their Fig. 1) suggest that for the vast majority of cases observed at SGP, $5 \%$ or less of the extinction will be found above $4 \mathrm{~km}$. For low-AOD cases $\left(\mathrm{AOD}_{355}<0.3\right)$ their mean extinction profiles suggest little to no aerosol extinction between 4 and $7 \mathrm{~km}$. At BND, Esteve et al. (2012) noted that CALIPSO data indicated negligible extinction above $4.6 \mathrm{~km}$ a.s.l. Regionally, seasonal average profiles from CALIPSO also suggest there is minimal aerosol above the flight's highest level (Ma and $\mathrm{Yu}, 2014$; $\mathrm{Yu}$ et al., 2010).

Although statistical profile results (e.g., Turner et al., 2001; Yu et al., 2010; Ma and Yu, 2014) suggest little contribution from high-altitude aerosol layers in the region of these two sites, Schutgens et al. (2016) demonstrate the importance of considering the specifics rather than the statistical. We used the Raman lidar best-estimate data product of extinction profiles at SGP to evaluate the presence of aerosol above the highest flight level at the site. For the SGP in situ profiles that had matches with AERONET inversion retrievals, we identified three lidar profiles that exhibited aerosol layers at high altitudes, but in all three cases the presence of these layers was also hinted at by an increase in the aerosol loading at the highest flight levels of the in situ measurement. Thus, we further screened in situ-AERONET comparisons by removing flights at SGP and BND with significant increases in loading at the highest flight levels. There may still be aerosol layers above the level measured by the Raman lidar, but we have no means of assessing that. The AOD comparison presented in Fig. 4 suggests we are unlikely to be missing significant aerosol at high altitudes.

Several papers (Andrews et al., 2004; Esteve et al., 2012; Sheridan et al., 2012) have shown that there is a high correlation $\left(R^{2}>0.8\right)$ between scattering measured at the surface site (SGP or BND) with scattering measured at the cor- responding lowest flight leg, although the slopes of the relationships indicated that the airplane measurements might be missing a fraction (10-20\%) of the aerosol below about $150 \mathrm{~m}$ a.g.l.. Additionally, Esteve et al. (2012) found high correlation (slope $=1.01, R^{2} \sim 0.7$ ) between scattering AOD calculated by assuming the lowest leg represented scattering in the entire layer between surface and flight leg with scattering AOD calculated from $1 \mathrm{~s}$ data obtained during descent from the lowest flight leg to landing. This result suggested that no consistent bias would result from assuming the lowest flight leg was representative of the aerosol between surface and that altitude. We looked at the relationship of the surface and lowest flight leg specifically for the flights with matching AERONET retrievals studied here. We found that at BND the surface and lowest-level flight aerosol measurements were virtually identical. At SGP the lowest-level leg actually measured slightly higher aerosol loading than was observed at the surface, which could lead to an overestimate of the aerosol optical depth in that layer, depending on the shape of the profile.

Similarly, Esteve et al. (2012) investigated differences in aerosol scattering between and at flight levels by comparing scattering AOD from the airplane descent between layers with that calculated from the individual level legs in the profile. Again they were able to confirm that measurements made during the fixed flight altitudes are representative of the aerosol near those altitudes.

\subsubsection{AERONET uncertainties}

Uncertainties in AERONET retrievals have been reported in several papers. Eck et al. (1999) indicate that the uncertainty in AOD is approximately 0.01 for a field-deployed AERONET sunphotometer at solar zenith angle $=0$ (i.e., sun directly overhead). For the almucantar retrievals (solar zenith angle $>50$ ) used here, the AOD uncertainty will be smaller as the uncertainty in AOD decreases inversely with air mass (Hamonou et al., 1999; their Eq. 1).

Dubovik et al. (2000) report AERONET-retrieved SSA uncertainties in their Table 4. For water-soluble aerosol (the predominant aerosol type at both BND and SGP) they report that SSA values are reliable to within \pm 0.03 when AOD440 $>0.2$, while the uncertainty in SSA increases to $( \pm 0.05-0.07)$ for AOD $440 \leq 0.2$. The almucantar retrieval of SSA may be biased by errors in the surface reflectance when the AOD is very low. Another potential issue is that the AERONET retrievals report only one pair of (real, imaginary) refractive index values for the total size distribution (for each wavelength). If there are two or more aerosol modes in the column, this assumption may skew the resulting SSA and AAOD values, although the effect of such skewing would depend on the aerosol properties and cannot be assessed here. Potential impacts in the case of uneven mode absorption in the retrieved size distribution have been found to be minor since the retrieved size distribution is more linked to forward 
scattering than absorption (O. Dubovik, personal communication, 2014).

Mallet et al. (2013) report an AAOD uncertainty of 0.01 but do not indicate whether or how the AAOD uncertainty would change with $\mathrm{AOD}_{440}$. Using the sum-of-squares propagation of errors to calculate the uncertainty in AAOD for both high and low AAOD cases results in an AAOD uncertainty of approximately \pm 0.015 for both high- and low-AOD cases (high $\mathrm{AOD}_{440}=0.5, \delta \mathrm{AOD}=0.01, \mathrm{SSA}=0.95$, $\delta \mathrm{SSA}=0.03, \quad \mathrm{AAOD}=0.026 ; \quad$ low $\quad \mathrm{AOD}_{440}=0.2$, $\delta \mathrm{AOD}=0.01, \mathrm{SSA}=0.95, \delta \mathrm{SSA}=0.07, \mathrm{AAOD}=0.011$ ). An AAOD uncertainty value of \pm 0.015 suggests an uncertainty of about $60 \%$ in $\mathrm{AAOD}$ for $\mathrm{AOD}_{440}=0.5$ and more than $140 \%$ uncertainty in AAOD for $\mathrm{AOD}_{440}<0.2$.

\section{Results}

In this section we first present comparisons of AOD, AAOD and SSA from the in situ measurements at BND and SGP with AERONET retrievals. This includes (1) direct comparisons of each in situ profile with contemporaneous AERONET retrievals, after which the BND and SGP comparisons are put in the wider context of a literature review of similar direct comparisons of in situ and AERONET AAOD and SSA; (2) seasonal comparisons of AOD, AAOD and SSA from Phase II AeroCom model results, AERONET retrievals and in situ measurements for BND and SGP; and, finally, (3) discussion of these results in the context of biases in determination of AAOD.

\subsection{BND and SGP: in situ vs. AERONET - direct comparisons}

Figures 4, 5 and 6 show the direct comparisons of AOD, AAOD and SSA at both 440 and $675 \mathrm{~nm}$. On all three plots, the blue points represent the same data set - each point indicates a flight for which there was one or more successful AERONET Level 2 almucantar retrievals within $\pm 3 \mathrm{~h}$ of the end of the flight profile (if there was more than one retrieval corresponding to a flight, the retrievals were averaged). The thin gray lines on the $440 \mathrm{~nm}$ plots indicate the reported (AERONET) or calculated (in situ) uncertainties in the data. Table 1 provides a comparison of the statistical values (median, mean and standard deviation) at $440 \mathrm{~nm}$ for each of the parameters at both of the sites for these direct comparisons (blue points in Figs. 4, 5 and 6). The low number of flights for which there are comparisons available ( $\sim 10 \%$ of total number of flights) indicates both the effects of AERONET's stringent cloud screening routine and the constraints imposed by the almucantar retrievals. In addition to limiting the number of comparisons available for this study, this limited data availability also has implications for modellers utilizing AERONET data - for example, Schutgens et al. (2016) showed the importance of temporal col- location in measurement-model comparisons. Figure 4 also contains red points - the red data points represent all directsun AERONET Level 2 AOD measurements during the $\pm 3 \mathrm{~h}$ window around the end of each profile. Depending on atmospheric conditions, there may be more than one AERONET measurement within $\pm 3 \mathrm{~h}$ of the end of each profile, which is why in Fig. 4 there are more red data points plotted than there are flights. The red points have not been averaged in order to provide an indication of the variability in AOD during the in situ profiling flight.

The comparison between in situ and AERONET AOD is important because it can be used to evaluate how well the in situ and AERONET data can be expected to agree and, thus, set the context for the AAOD and SSA comparisons. Many studies have investigated the relationship between in situ and remotely sensed AOD (e.g., Crumreyrolle et al., 2014; Schmid et al., 2009, and references therein). As noted in these studies, the in situ derived AOD values tend to be slightly lower than the AOD retrieved from remote sensing measurements. Figure 4 presents the comparison of Level 2 AOD for AERONET and in situ measurements at 440 and $675 \mathrm{~nm}$ for two sets of AERONET AOD data. The first comparison (red points on plots) is for all direct-sun AERONET Level 2 AOD measurements. The second comparison (blue points on plots) is for flight-averaged AERONET Level 2 AOD measurements where all the criteria required for almucantar retrievals are satisfied. Table 2 summarizes how many points make up each of these data sets.

In general, Fig. 4 shows that AERONET AOD tends to be higher than the in situ AOD, although there is good correlation between AERONET and in situ AOD. The uncertainty bars tend to overlap the $1: 1$ line, suggesting that in situ measurements provide a reasonable proxy of the total column aerosol loading as represented by AERONET AOD. Student $t$ test evaluation suggests that the AERONET and in situ AODs are the same at the $95 \%$ confidence level. The coefficients of determination $\left(R^{2}\right)$ are within the range we would expect based on the lag-autocorrelation of scattering at these two sites (Fig. 2) and the $\pm 3 \mathrm{~h}$ time window. The $R^{2}$ values increase when subsetted for the more restrictive Level 2 almucantar retrievals. The lower in situ AOD values observed at both sites, compared to AERONET, may be due to the hygroscopicity adjustment from dry in situ to ambient RH conditions being too low or undersampling of larger particles (e.g., Esteve et al., 2012). Esteve et al. (2012) found slopes closer to 1 when they restricted AERONET-in situ AOD comparison to low ambient $\mathrm{RH}(<60 \%)$ conditions, although the AERONET AOD values were still larger than the in situ AOD. The effect of undersampling larger particles or underestimating aerosol hygroscopicity on the AAOD and SSA comparisons is discussed in Sect. 3.1.2. Some of the discrepancy between the in situ and the AERONET values may also be due to the limited vertical range covered by the airplane (150-4200 m a.s.l.). We excluded flights that might have had significant aerosol above the highest flight 
Table 1. (a) Statistical values (medians, means and standard deviations) of AERONET versus in situ comparison where there was an AERONET retrieval within $\pm 3 \mathrm{~h}$ of the end of a $2 \mathrm{~h}$ flight profile. AERONET values are for Level 1.5 data when there was a Level 2 AOD value and an almucantar retrieval. (First value in each cell is median; second set of values in each cell are mean \pm SD; third row is number of AERONET retrievals corresponding to flights (in AERONET columns) or number of flights (in situ columns).) These numbers represent the blue points in Figs. 4-6. (b) Statistical values (medians, means and standard deviations) of AERONET versus in situ comparison where there was an AERONET retrieval within $\pm 3 \mathrm{~h}$ of the end of a $2 \mathrm{~h}$ flight profile and AERONET AOD $440>0.2$. AERONET values are for Level 1.5 data when there was a Level 2 AOD value and an almucantar retrieval. (First value in each cell is median; second set of values in each cell are mean $\pm \mathrm{SD}$; third row is number of AERONET retrievals corresponding to flights (in AERONET columns) or number of flights (in situ columns).) These numbers represent the purple points in Figs. 5-6.

\begin{tabular}{lrrrr}
\hline & \multicolumn{3}{c}{ SGP } \\
\cline { 2 - 5 } (a) & AERONET & In situ & AERONET & In situ \\
\hline AOD & $0.118 ;$ & $0.114 ;$ & $0.138 ;$ & $0.137 ;$ \\
& $0.146 \pm 0.099$ & $0.135 \pm 0.139$ & $0.146 \pm 0.099$ & $0.147 \pm 0.077$ \\
AAOD & $0.013 ;$ & $0.003 ;$ & $0.019 ;$ & $0.004 ;$ \\
& $0.013 \pm 0.007$ & $0.005 \pm 0.006$ & $0.023 \pm 0.008$ & $0.004 \pm 0.003$ \\
SSA & $0.895 ;$ & $0.961 ;$ & $0.847 ;$ & $0.971 ;$ \\
& $0.898 \pm 0.034$ & $0.964 \pm 0.020$ & $0.839 \pm 0.038$ & $0.973 \pm 0.011$ \\
No. & 51 retrievals* & 21 flights & 23 retrievals* & 11 flights \\
\hline (b) & & & & 0.238 \\
\hline AOD & $0.306 ;$ & $0.299 ;$ & 0.269 & 0.009 \\
AAOD & $0.304 \pm 0.125$ & $0.331 \pm 0.230$ & & 0.034 \\
SSA & $0.025 ;$ & $0.010 ;$ & & 0.964 \\
& $0.942 \pm 0.023$ & $0.966 \pm 0.010$ & & \\
No. & 6 retrievals* & 4 flights & 2 retrievals & 1 flights \\
\hline
\end{tabular}

* Retrievals are flight-averaged prior to calculating statistics.

Table 2. Number of AERONET-in situ AOD and AAOD flight matches as a function of various AERONET constraints and the $\pm 3 \mathrm{~h}$ time window.

\begin{tabular}{lrr}
\hline & BND (2006-2009) & SGP (2005-2007) \\
\hline Total profile flights & 402 & 171 \\
\hline Level 2 AOD & 73 & 37 \\
Level 2 AOD + almucantar retrieval* & 21 & 11 \\
Level 2 AOD + almucantar retrieval + AOD $440>0.20$ & 2 & 1 \\
\hline Level 1.5* AAOD & 21 & 11 \\
Level 1.5* AAOD + AOD $440>0.20$ & 4 & 0 \\
Level 2 AAOD & 1 & \\
\hline
\end{tabular}

* An almucantar retrieval does not necessarily imply an AAOD retrieval.

level, based on Raman lidar comparisons (at SGP) and profile shapes (at BND). The relationships observed between AERONET and in situ AOD for both sites are very similar to those observed for the recent DISCOVER-AQ campaign (e.g., Crumreyrolle et al., 2014, their Fig. 3).

One thing to note on Fig. $4 \mathrm{a}$ is the blue point marked BB (the BB stands for biomass burning). This measurement occurred on 28 June 2006 and appears to have been strongly affected by forest fire smoke transported from Canada. We applied the same hygroscopicity adjustment to the measurements of this flight as we did to all of the BND flights and, in this $\mathrm{BB}$ case, the hygroscopicity correction was the primary reason the in situ AOD value is significantly higher than the AERONET AOD value. This point would lie much closer to the $1: 1$ line if the in situ BB data were assumed to be hygrophobic. Previous work at the surface site at SGP has shown 
that dust and smoke aerosol types tend to exhibit lower hygroscopicity than the background aerosol normally observed at the site (Sheridan et al., 2001). This BB point provides an extreme example of the downside of using a constant hygroscopic growth parameter as a function of $\mathrm{RH}$, although without additional information about the aerosol for each profile it is difficult to do otherwise. The light blue dotted line on Fig. 4 represents the relationship between AERONET and in situ data if the BB point is excluded.

Figure 5 presents the comparison of AAOD for flightaveraged AERONET and in situ measurements. As described above, the AERONET AAOD values shown in Fig. 5 are what we have termed Level $1.5^{*}$ data - i.e., they are from Level 1.5 almucantar retrievals when there was a valid Level 2 almucantar retrieval, but the $\mathrm{AOD}_{440}>0.4$ constraint was not applied. In contrast to the AOD comparison depicted in Fig. 4, the AERONET Level 1.5* AAOD values are significantly higher than the in situ AAOD values. Figure 5 also shows that the correlation between the AERONET and in situ AAOD is poorer than it was for AOD, particularly at BND ( $R^{2}$ is 0.49 at BND and 0.68 at SGP for the $440 \mathrm{~nm}$ comparison). The lower correlation at BND is somewhat surprising given the lag-autocorrelation results for aerosol absorption (Fig. 2a) at the BND surface site. Surprisingly, while the BND site has higher $3 \mathrm{~h}$ autocorrelations for absorption than SGP ( $R=0.75$ for BND and $R=0.55$ for SGP, per Fig. 2 ), the results for BND in Fig. 5 indicate less correlation than at SGP for absorption. Nonetheless, the correlation coefficients for BND in Fig. $5\left(R^{2}=0.49\right.$ (blue) and 0.37 (red) correspond to $R=0.70$ (blue) and 0.61 (red)) are not that far from the $3 \mathrm{~h}$ autocorrelation of $r(k=3 \mathrm{~h})=0.75$ for absorption at BND in Fig. 2. For AAOD the uncertainty bars, while wider, exhibit significantly less overlap with the $1: 1$ line (indeed no overlap at SGP) and the Student $t$ test suggests the AERONET and in situ AAOD values are different at the $95 \%$ level at both sites.

Both Fig. 5 and the median values provided in Table 1 indicate that AERONET Level 1.5* AAOD tends to be larger than the in situ AAOD, although the scatter in the relationships (particularly at BND) suggests that a multiplicative factor does not represent the relationship very well. The purple points in Fig. 5 indicate AAOD retrievals where the flightaveraged $\mathrm{AOD}_{440}>0.2$. There is no obvious improvement of the relationship between in situ and AERONET AAOD when these points are considered (although there are only 1-4 comparison points above $\mathrm{AOD}_{440}>0.2$ for each site).

The AAOD comparisons at $675 \mathrm{~nm}$ at BND (Fig. 5c) are quite similar to those at $440 \mathrm{~nm}$, suggesting that there is little contribution to absorbing aerosol from dust, organic carbon and/or $\mathrm{NO}_{2}$. In contrast, at SGP, there is a change in the relationship between AERONET and in situ AAOD from 440 to $675 \mathrm{~nm}$, indicating that one or more of these components may affect the $440 \mathrm{~nm}$ comparisons at that site (Fig. 5d). Recent work by Engelbrecht et al. (2016) has suggested that even at $405 \mathrm{~nm}$ most dusts have SSA values $>0.9$, meaning they are not much more absorbing than the aerosol typically observed at BND and SGP. Further, Ångström exponent values from the matched AERONET and in situ profile data do not support the presence of dust, while the rural nature of the site suggests significant levels of $\mathrm{NO}_{2}$ are unlikely. Thus the most likely explanation is the presence of organic carbon, although the IMPROVE sulfate and organic data used to estimate aerosol hygroscopicity do not support this. The IMPROVE measurements tend to suggest a relatively small contribution of organics to the aerosol mass with the average mass concentration of organics only 40 to $60 \%$ that of sulfate aerosol mass concentration for BND and SGP, respectively. In contrast, the Aerosol Chemical Speciation Monitor (ACSM) measurements by Parworth et al. (2015) indicate that, depending on the month, organic aerosol can contribute up to $70 \%$ of the total aerosol mass at SGP.

Figure 6 presents the comparison of column SSA retrieved from flight-averaged AERONET inversions (Level 1.5* data) with the column SSA calculated from in situ profile measurements of aerosol scattering and absorption at BND and SGP. Consistent with the AOD and AAOD comparisons (Figs. 4 and 5) the SSA retrieved from AERONET tends to be much lower than the SSA calculated from the in situ profile measurements. As with AAOD, the SSA uncertainty bars exhibit little overlap with the $1: 1$ line and a Student $t$ test suggests the AERONET and in situ SSA values are different at the $95 \%$ level for both BND and SGP. At both sites the range in AERONET-retrieved SSA is much wider than the range in column SSA obtained from the in situ profiles. Long-term, in situ measurements at the BND and SGP surface sites yield mean SSA values of 0.92 and 0.95 , respectively (Delene and Ogren, 2002, based on monthly-averaged data). Delene and Ogren's (2002) surface SSA values are reported at low RH $(\mathrm{RH}<40 \%)$ and $550 \mathrm{~nm}$; adjusting them to ambient conditions and $440 \mathrm{~nm}$ would likely cause them to increase, making them more comparable to the in situ column SSA depicted in Fig. 6 but even less like the AERONET Level 1.5* SSA values. As with Fig. 5, the purple points on Fig. 6 indicate when the flight-averaged $\mathrm{AOD}_{440}>0.2$; although there are not enough points to draw a robust conclusion, there does not appear to be an improvement in the relationship between in situ and AERONET SSA when only these purple points are considered.

Figure 6 also includes a set of "hybrid SSA" ( SSA $\left._{\text {hybrid }}\right)$ points in yellow. These points have been calculated using the AERONET AOD and the in situ AAOD:

$\mathrm{SSA}_{\text {hybrid }}=\left(\mathrm{AOD}_{\mathrm{AERONET}}-\mathrm{AAOD}_{\mathrm{PSAP}}\right) / \mathrm{AOD}_{\mathrm{AERONET}}$.

This hybrid approach to SSA eliminates the uncertainty associated with the empirical hygroscopic growth factors applied to the in situ scattering measurements and also removes the scattering uncertainty associated with undersampling the coarse mode. It does not, however, eliminate the uncertainties 

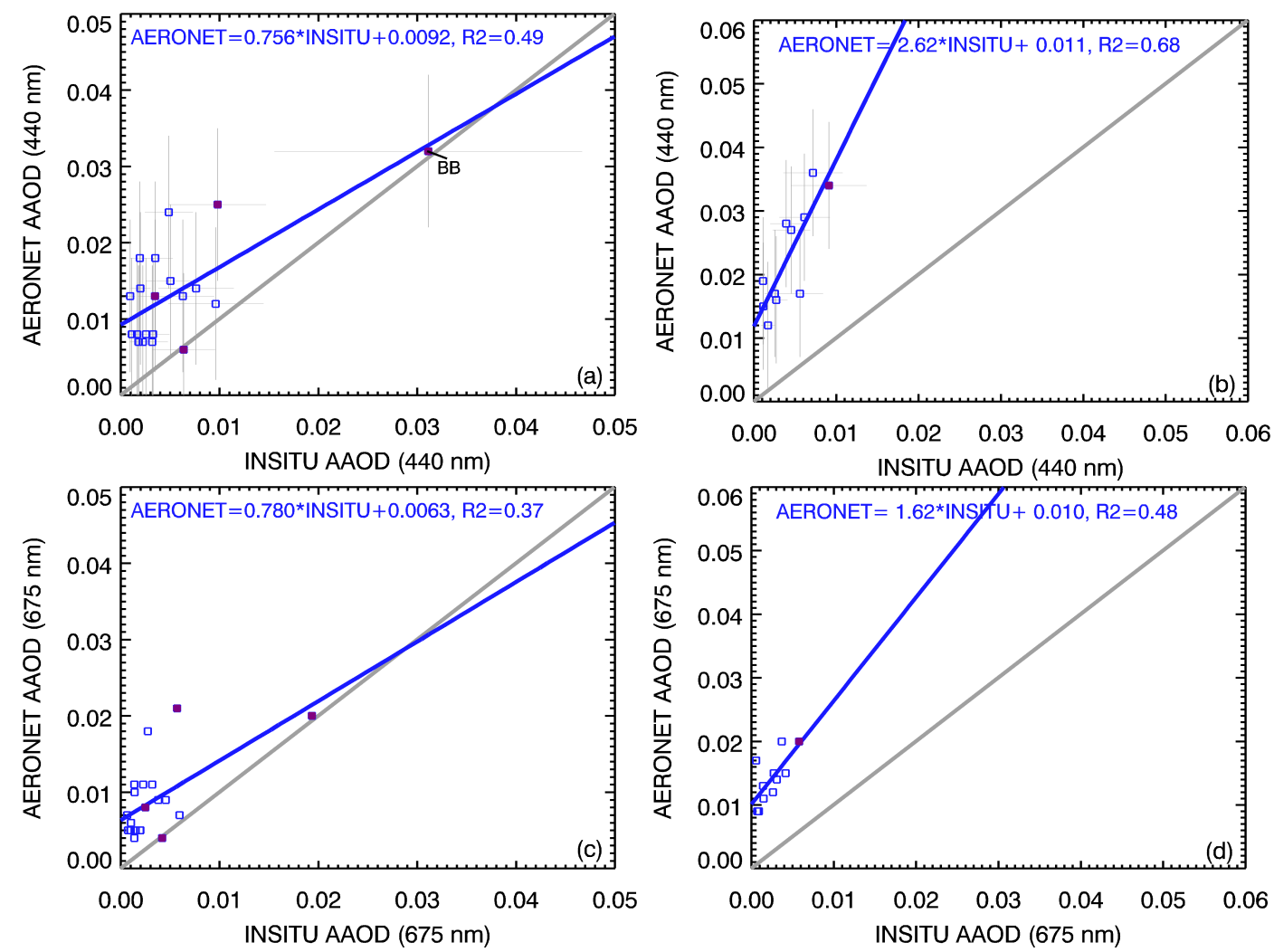

Figure 5. AAOD comparison: (a) BND at $440 \mathrm{~nm}$, (b) SGP at $440 \mathrm{~nm}$, (c) BND at $675 \mathrm{~nm}$ and (d) SGP at $675 \mathrm{~nm}$. Blue line is linear fit for all points shown; gray line is 1-to-1 line. Thin gray lines associated with each data point represent measurement uncertainties. Points show the average of AERONET Level 1.5 AAOD retrievals for which there was a successful AERONET Level 2 almucantar retrieval within $\pm 3 \mathrm{~h}$ of end of profile. Purple points indicate the few comparisons points for which there are AERONET Level 2 almucantar retrievals and where the average AERONET AOD 440 for those retrievals was great than 0.2.

associated with assuming the absorbing aerosol is hygrophobic, there is little absorption in the potentially undersampled coarse mode or the unknown contribution from absorption enhancement. $\mathrm{SSA}_{\text {hybrid }}$ is very similar to the SSA derived from in situ measurements, suggesting the primary discrepancy between the AERONET SSA and the in situ SSA is due to the determination of the absorbing nature of the aerosol related either to issues with the limitations of the filter-based measurements or to the interpretation of the relative contribution of aerosol absorption from the AERONET inversion retrieval products.

\subsection{How might in situ hygroscopicity assumptions and undersampling of the aerosol affect SSA and AAOD comparisons?}

Figure 4 shows that the AERONET AOD may be slightly larger than the in situ AOD, while Figs. 5 and 6 suggest that the AERONET retrievals significantly overestimate the amount of absorbing aerosol (low SSA, high AAOD) relative to the in situ measurements. The slight deviation between in situ and AERONET AOD may lead to questions about whether directly comparing other AERONET and in situ parameters (e.g., SSA, AAOD) is a reasonable thing to do and whether the AAOD and SSA comparisons shown in Figs. 5 and 6 are related to issues with the AOD comparison. As mentioned above, Esteve et al. (2012) suggested the AOD difference was most likely due to either underestimating the hygroscopic growth correction or undersampling of supermicron particles by the aircraft inlet. In this section we evaluate how these two possible causes of the AOD discrepancy might affect the SSA and AAOD comparisons.

Increasing the hygroscopic growth adjustment of the in situ measurements would enhance the in situ scattering values used to calculate the in situ AOD but would not change the in situ AAOD because the absorbing particles are assumed to be non-hygroscopic. Consequently, the comparison depicted in Fig. 5 would not change with a different adjustment for hygroscopic growth. Increasing the in situ AOD, without affecting the in situ AAOD, would result in higher in situ SSA values and an even greater discrepancy between AERONET and in situ SSA values than shown in Fig. 6. To evaluate the effect of assuming absorbing particles were non-hygroscopic, a sensitivity test was performed assuming the absorption enhancement due to RH was 

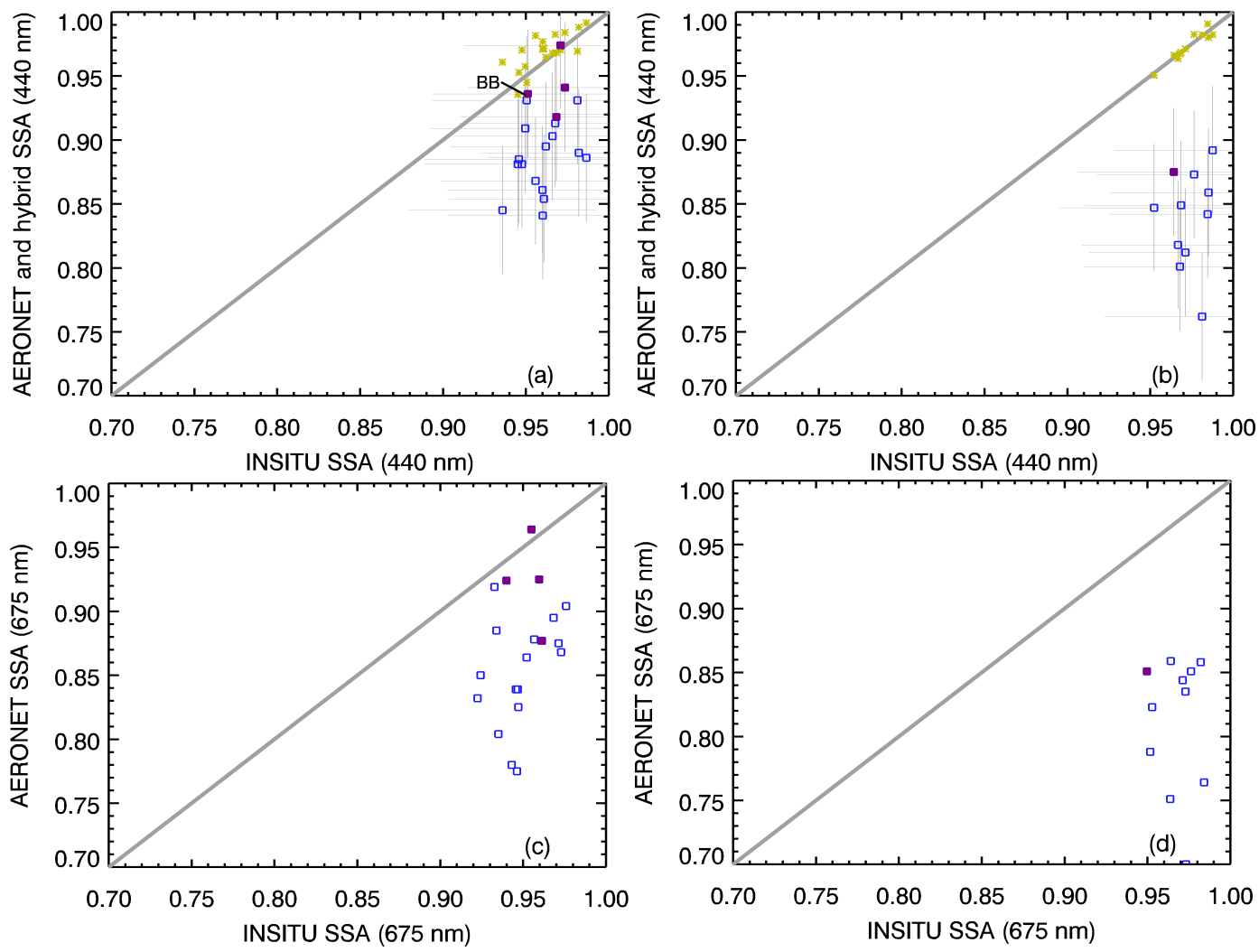

Figure 6. SSA comparison: (a) BND at $440 \mathrm{~nm}$, (b) SGP at $440 \mathrm{~nm}$, (c) BND at $675 \mathrm{~nm}$ and (d) SGP at $675 \mathrm{~nm}$. Blue line is linear fit for all points shown; gray line is 1-to-1 line. Thin gray lines associated with each data point represent measurement uncertainties. Blue points show the average of all AERONET Level 1.5 AAOD retrievals for which there was a successful AERONET Level 2 almucantar retrieval within $\pm 3 \mathrm{~h}$ of end of profile. Purple points indicate the few points for which there are AERONET Level 2 almucantar retrievals and where the average AERONET AOD 440 for those retrievals was great than 0.2. The yellow points represent the "hybrid SSA", which utilizes the AERONET AOD and the in situ AAOD to derive SSA as described in the text. The in situ uncertainty lines here represent SSA uncertainty of 0.06 , which is the worst-case uncertainty.

the same as the hygroscopicity scattering enhancement, i.e., $\sigma_{\mathrm{ap}}\left(\mathrm{RH}_{\mathrm{amb}}\right) / \sigma_{\mathrm{ap}}\left(\mathrm{RH}_{\mathrm{dry}}\right)=a \times\left(1-\left(\mathrm{RH}_{\mathrm{amb}} / 100\right)\right)^{-\gamma}$. While this is likely an extreme assumption, it had minimal effect on the comparisons of AOD, AAOD and SSA.

The other likely candidate to explain the in situ AOD being slightly lower than the AERONET AOD is aircraft undersampling of super-micron aerosol particles due to the $5 \mu \mathrm{m}$ inlet cutoff. The Esteve et al. (2012) comparison of column in situ and AERONET scattering Ångström exponents at BND suggested that the airplane measurements might be undersampling larger particles. Sheridan et al. (2012) estimated that the aircraft inlet $50 \%$ cutoff aerodynamic diameter is approximately $5 \mu \mathrm{m}$, so particles larger than that are unlikely to be sampled by the in situ measurements but will be sensed by the AERONET sunphotometer. If we take into account that atmospheric particles are likely to have a density greater than $1 \mathrm{~g} \mathrm{~cm}^{-3}$, the actual cut size would be closer to 3 or $4 \mu \mathrm{m}$. The AERONET volume size distributions were used to estimate the fraction of column extinction due to particles less than $3 \mu \mathrm{m}$. At
BND the mean and standard deviation of the $3 \mu \mathrm{m}$ extinction fraction (extinction $(D<3 \mu \mathrm{m}) /$ extinction $(D<30 \mu \mathrm{m})$ ) was $0.93 \pm 0.07$, while at SGP the extinction fraction value was $0.88 \pm 0.09$. At the BND and SGP surface sites, most (80-90\%) of the observed sub-10 $\mu \mathrm{m}$ scattering and absorption is also attributed to submicron aerosol, with absorption more likely to be in the submicron size range than scattering (Delene and Ogren, 2002; Sherman et al., 2015). This is consistent with the observation that absorbing aerosol tends to be concentrated in submicron particles for typical aged continental air masses (e.g., Hinds, 1982). Based on these observations, larger and primarily scattering particles are more likely to be undersampled by the in situ measurements than absorbing particles. This is the opposite of what is needed to explain the discrepancies between AERONET and in situ AOD, AAOD and SSA shown in Figs. 4-6. The in situ measurements would need to preferentially undersample absorbing aerosol relative to scattering aerosol in order to come into line with the AERONET observations. Additionally, Sheridan et al. (2012) calculated particle transmission losses from 
behind the sample inlet on the airplane to both the nephelometer and PSAP to be similar and to be less than $10 \%$ in the particle diameter range $0.01<D<1 \mu \mathrm{m}$. This suggests that preferential losses of absorbing aerosol are also unlikely to occur downstream of the aerosol inlet. In summary, we can only see two ways that the in situ measurements can sample aerosol efficiently enough to represent AERONET AOD fairly well but significantly underestimate AAOD and overestimate SSA: (1) not accounting properly for the effect of coatings (organic or water) on absorption enhancement which we discussed in detail in Sect. 2.4.1 and (2) not sampling layers of predominantly absorbing aerosol below, between and/or above the flight layers. We suspect that the SSA required of such layers in order to explain the AAOD and SSA discrepancies is physically impossible.

\subsection{Literature survey: in situ vs. AERONET - direct comparisons}

Direct comparisons at BND and SGP suggest that AERONET retrievals underestimate SSA and, consequently, that AERONET overestimates AAOD relative to in situ measurements of AAOD for the low-AOD conditions typical at these two sites. The next question to address is whether this discrepancy, found for two rural, continental sites in the central US with relatively low aerosol loading, is more widely observed for direct in situ-AERONET comparisons at a variety of sites/conditions. As in Sect. 3.1, the focus in this section is on direct comparisons of column-averaged SSA (or AAOD) derived from in situ measurements made during aerosol profiling flights that were flown in close proximity (temporal and spatial) to an AERONET retrieval. Tables 3 and 4 summarize literature results describing the direct comparisons of AERONET retrievals with in situ aerosol profile measurements for AAOD and column SSA. Figure 7 provides a graphical overview of the SSA comparisons described in Table 4. Tables 3 and 4 and Fig. 7 also include the BND and SGP comparisons described in this study. With the possible exception of some of the profiles reported by Corrigan et al. (2008), the literature comparisons cited in Tables 3 and 4 and shown in Fig. 7 have been made at higher AOD conditions $\left(\mathrm{AOD}_{440}>0.3\right)$ to reduce retrieval uncertainty. In contrast, the SGP and BND comparisons are more representative of global AOD (Fig. 1) with the majority of the comparisons at BND and SGP occurring for $\mathrm{AOD}_{440}<0.2$. Please note that some of the earlier studies shown in Fig. 7 and described in Table 4 used values from Version 1 AERONET Level 2.0 data. Where that was the case, we retrieved Version 2 AERONET Level 2.0 data from the AERONET website and those Version 2 data are reported in Table 4 and depicted in Fig. 7. The comment section of Table 4 mentions the cases where this was done. For some of these references we also retrieved the $\mathrm{AOD}_{440}$ values from the AERONET website as the $\mathrm{AOD}_{440}$ values were not reported in all papers.

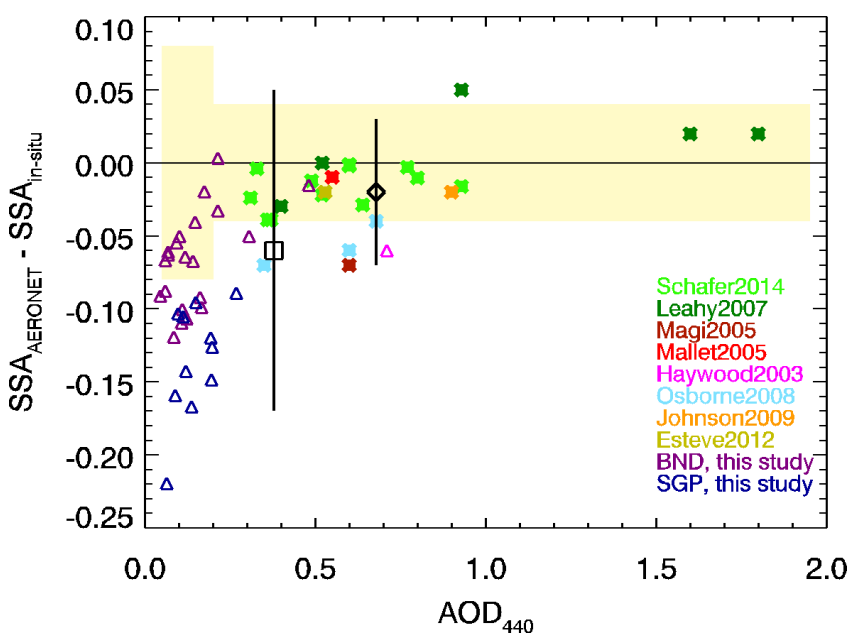

Figure 7. $\mathrm{AOD}_{440}$ vs. $\left[\mathrm{SSA}_{\mathrm{AERONET}}-\mathrm{SSA}_{\text {INSITU }}\right]$ for direct comparisons studies listed in Table 4. Open symbols are for $\mathrm{SSA}_{440}$ difference; filled symbols are for $\mathrm{SSA}_{550}$ difference. $\mathrm{AOD}_{440}$ values for Leahy2007, Osborne2008 and Johnson2009 use the Level 2 values reported on the AERONET web page for the locations and dates of the specific profile. Shading indicates the combined standard uncertainty of AERONET SSA values as function of AOD as reported in Table 4 of Dubovik et al. (2000) and uncertainty in the in situ SSA based on Fig. 2. The black square and black diamond with vertical black lines represent, respectively, the mean and $2 \times$ standard deviation for all direct comparisons (including BND and SGP) and for literature direct comparisons only.

Tables 3 and 4 have been restricted to studies with direct comparisons of column-averaged AAOD or SSA retrieved from full in situ vertical profiles flown near (within $\sim 100 \mathrm{~km})$ AERONET sites within a few hours of the AERONET retrieval, i.e., studies that are comparable to the BND and SGP studies described in Sect. 3.1. For non-plume data sets, Anderson et al. (2003) found autocorrelations $>0.8$ at $100 \mathrm{~km}$ (their Fig. 6). For plume-influenced data sets they found autocorrelations $\sim 0.6$. Included in the tables are the field campaign name (if applicable), number of AAOD or SSA comparisons, the primary type of aerosol studied, summary of AOD comparisons (if available), altitude range covered by the airplane, instruments and data processing (e.g., instrument corrections, treatment of hygroscopicity, wavelength adjustment) and a summary of the results of the AAOD comparison. The last column in Tables 3 and 4 includes information on the spatial and temporal differences between the in situ measurements and AERONET retrievals and comments on treatment of the AERONET and in situ data. The last column also notes how each campaign dealt with aerosol below and above the in situ profile if reported. It should be noted that the number of SGP and BND comparisons of AAOD and SSA in Tables 3 and 4 are only possible because we utilized AERONET retrievals below the recommended threshold of $\mathrm{AOD}_{440}>0.4$. The uncertainty for the $\mathrm{BND}$ and SGP comparisons is much higher than for some of 


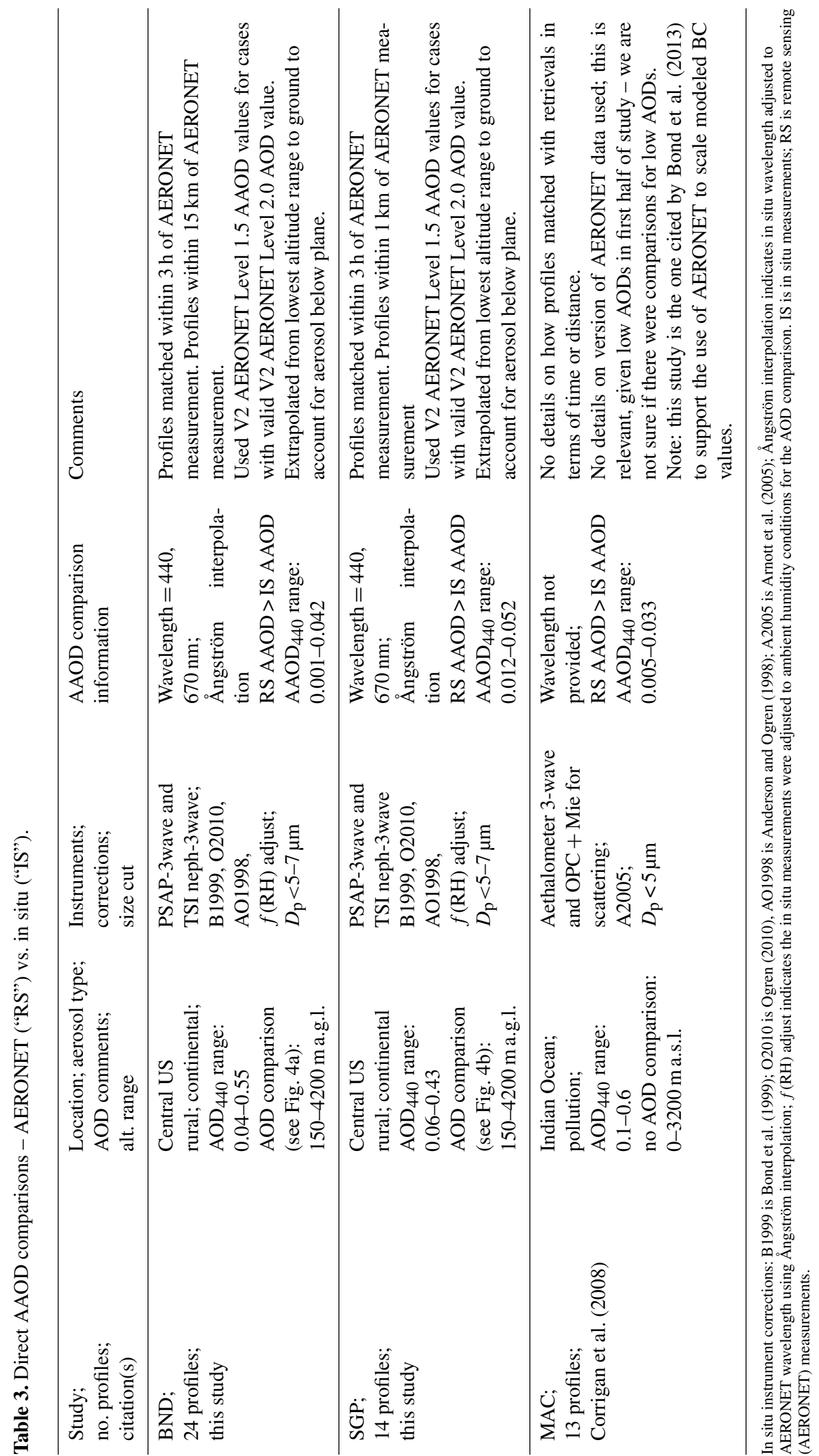




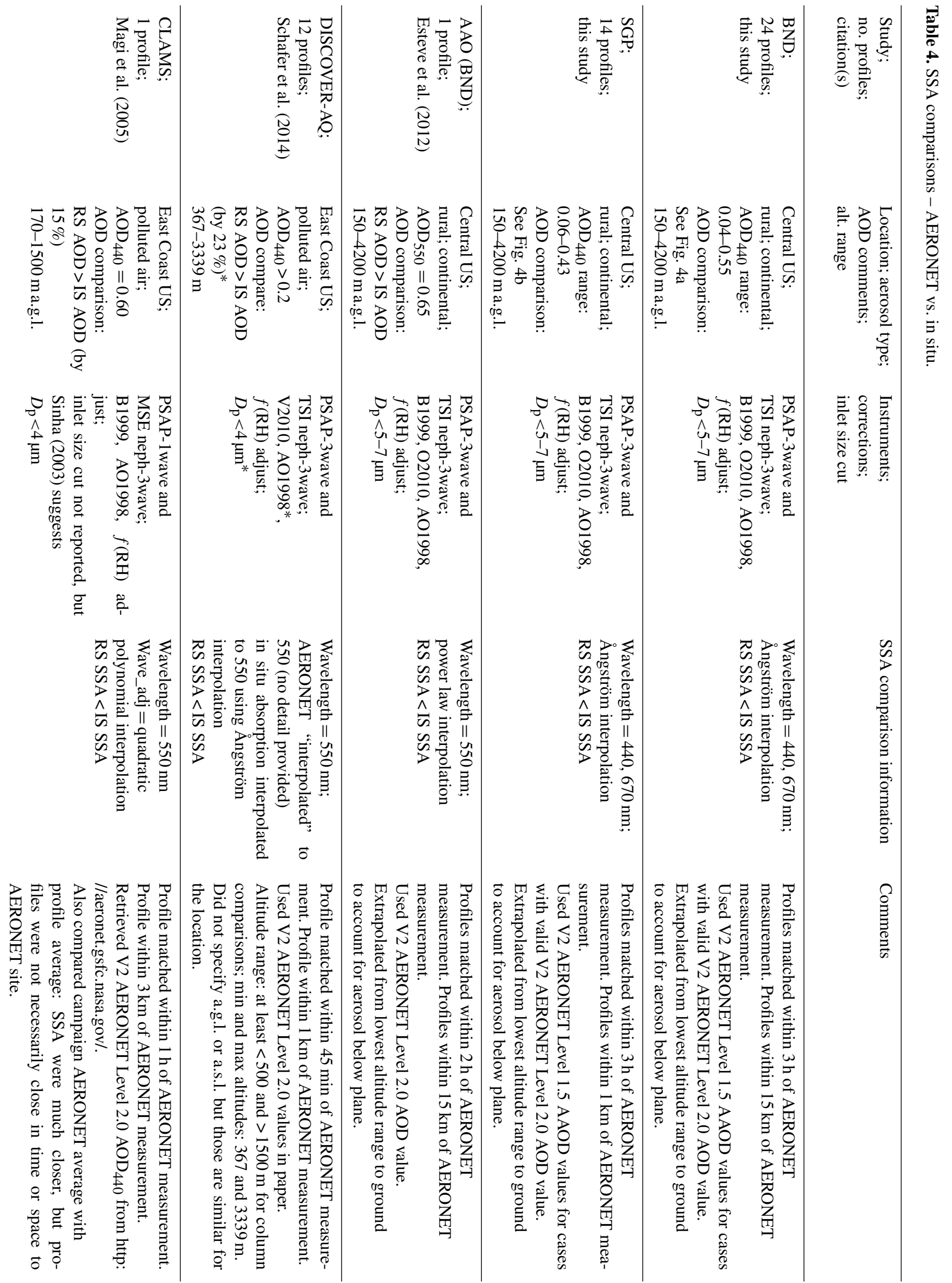




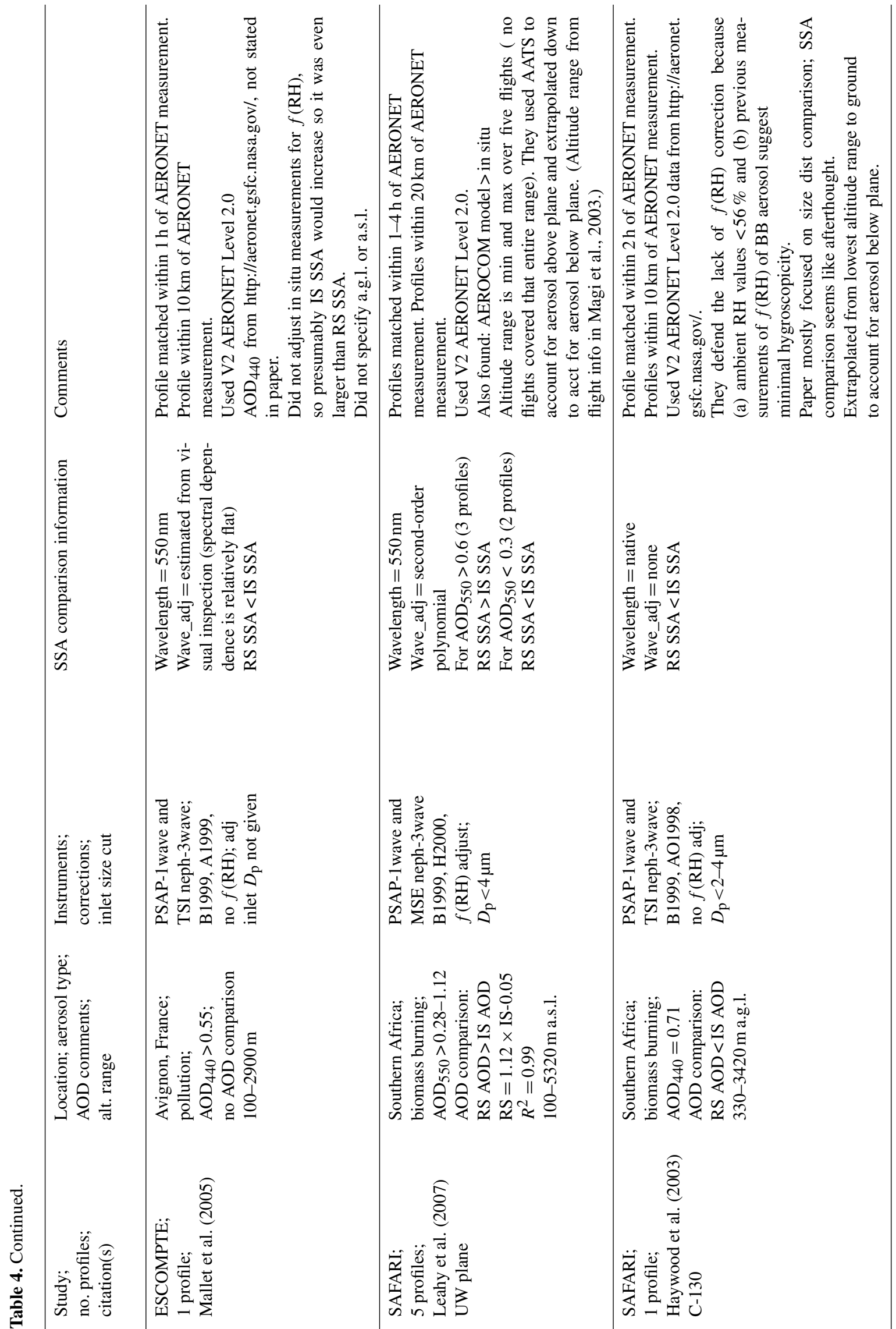



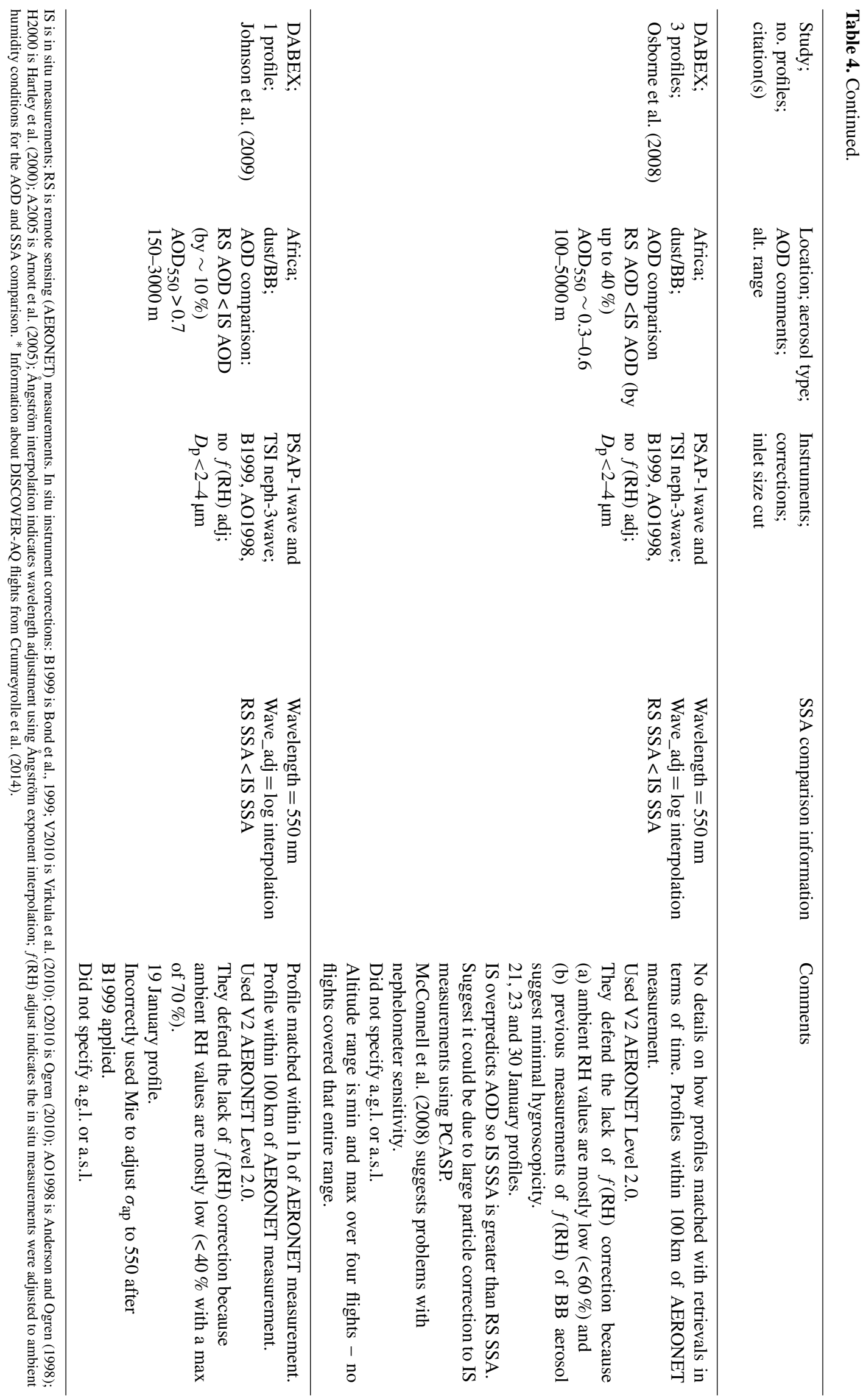
the other direct comparisons due to the low-AOD conditions observed at these sites.

For the three AAOD closure studies listed in Table 3 (the BND and SGP results presented here, plus results from a field campaign over the Indian Ocean) the AERONET retrievals indicate more absorbing aerosol in the column than is suggested by the corresponding in situ measurements. The Corrigan et al. (2008) paper mentioned in Table 3 is the sole AERONET-in situ AAOD comparison cited by Bond et al. (2013), as it was the only published direct AAOD comparison available. Corrigan et al. (2008) present no AOD comparisons that could provide an indication of their sampling system efficiency, and information about the wavelength of the comparisons and profiles specifics is lacking. To our knowledge, no other direct comparisons of in situ and AERONET AAOD are available in the literature.

The SSA comparison studies listed in Table 4 and visually summarized in Fig. 7 indicate that, even at higher AOD, AERONET retrievals tend to indicate more-absorbing aerosol (lower SSA) relative to in situ measurements, although most of the values are within the combined standard uncertainty of the AERONET and in situ values indicated by the shading (see BIPM, 2008, their Eq. 16, for how the combined standard uncertainty was calculated). Of the 63 cases depicted in Fig. 7, 16 cases $(\sim 25 \%)$ of the AERONET-in situ comparisons were within 0.02. While much of the observed difference between SSAINSITU and $\mathrm{SSA}_{\mathrm{AERONET}}$ may fall within the uncertainty of the SSA values, as noted in Schafer et al. (2014), the fact that the difference $\left(\mathrm{SSA}_{\mathrm{AERONET}}-\mathrm{SSA}_{\text {INSITU }}\right)$ is predominately negative across all the direct comparisons found in the literature is not what would be expected from random error. Figure 7 also shows the mean and $2 \times$ standard deviation of all of the points (black square and vertical lines) and just the literature value points (black diamond and vertical lines). Based on the characteristics of a normal distribution the standard deviation lines suggest $\sim 80 \%$ of the points will be negative - random error would suggest only $50 \%$ of the points should be negative. Figure 7 suggests that AERONET retrievals of SSA could perhaps be used at $\mathrm{AOD}_{440}<0.4$, perhaps down to $\mathrm{AOD}_{440} \sim 0.25$ or $\sim 0.3$ - even at those low-AOD values the differences in SSA between AERONET and in situ still tend to be within the AERONET uncertainty. However, as Fig. 7 shows, there are not a lot of direct comparisons to support such a choice.

Most of the SSA comparisons in Table 4 reported fairly good agreement between AERONET and in situ AOD, implying that the discrepancy is associated with the absorption values rather than the scattering values (since scattering is typically $90 \%$ of extinction). This is consistent with the AERONET AAOD values being greater than those obtained from in situ measurements presented in Table 3. Out of the 63 profiles compared in Table 4, there are four exceptions, (three from Leahy et al., 2007, and one from this study for

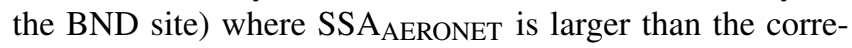

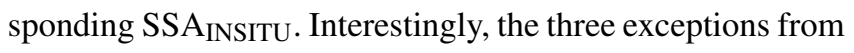
Leahy et al. (2007) were for their high-AOD $\left(\mathrm{AOD}_{550}>0.6\right)$ cases; for their two low-AOD $\left(\mathrm{AOD}_{550}<0.3\right)$ cases the opposite was found, i.e., $\mathrm{SSA}_{\mathrm{AERONET}}<\mathrm{SSA}_{\text {INSITU }}$.

In summary, the literature survey featuring measurements across the globe for many aerosol types suggests that even at higher AOD conditions, direct comparisons of AERONET with in situ aerosol profiles find that AERONET column SSA is consistently lower than the SSA obtained from in situ measurements (although mostly within the uncertainty of the AERONET SSA retrieval and in situ measurements). If there was no consistent bias in the AERONET-INSITU comparison we would expect AERONET_SSA-INSITU_SSA to be evenly distributed around zero. Instead, Fig. 7, which summarizes the literature survey, suggests that either AERONET retrievals are biased towards too much absorption or in situ, filter-based measurements of aerosol absorption are biased low. We note that the results from the literature (e.g., Fig. 7) indicate that the hypothesized low bias in in situ absorption is not associated with a single airplane's measurement system or the atmospheric conditions encountered in a single experiment. That leaves us with possible bias in the in situ experimental methods (instrument issues (nephelometer, PSAP), treatment of $f(\mathrm{RH})$, vertical coverage, sampling artifacts), all of which we have attempted to address above.

An alternative explanation is that the AERONET SSA uncertainties are nonsymmetric. Dubovik et al. (2000) suggest that simulated retrievals of SSA for "water-soluble aerosol" are asymmetric when different "instrumental offsets" are assumed, particularly at lower AOD values (0.05 and 0.2). Their Fig. 4 shows a much larger decrease in SSA for some instrumental offsets relative to the increase in SSA observed for an instrumental offset of the same magnitude but opposite sign. Asymmetry is also indicated for "biomass burning" aerosol (their Fig. 7) although the asymmetry is in the opposite direction, i.e., the increase in SSA is larger than the decrease for a given pair of instrumental offset values. It is not obvious from their Fig. 7 whether the retrievals are asymmetric for simulated dust aerosol. Interestingly, at least three of the four points in Fig. 7 with AERONET_SSA > INSITU_SSA represent retrievals of biomass burning aerosol.

\subsection{BND and SGP: in situ vs. AERONET and AeroCom model output - statistical comparisons}

Most of the statistical comparisons between AERONET and in situ profiles (e.g., Ramanathan et al., 2001; Leahy et al., 2007; Ferrero et al., 2011; Johnson et al., 2011) were for short-term field campaigns with a limited number of in situ profiles. The advantage of the multi-year, in situ vertical profiling programs at BND (401 flights) and SGP (302 flights) is that we can compare the statistics for both in situ and AERONET values as opposed to comparing individual in situ values to remote retrieval statistics. Figure 1 in Andrews et 
(a)

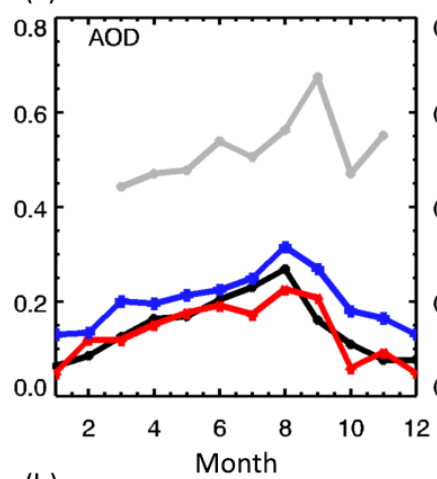

(b)

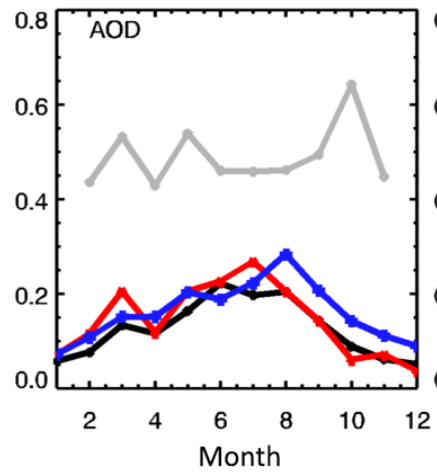

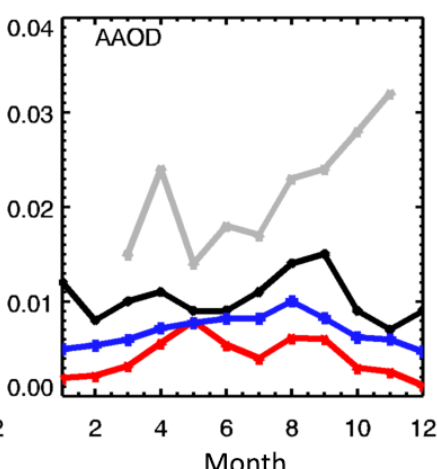

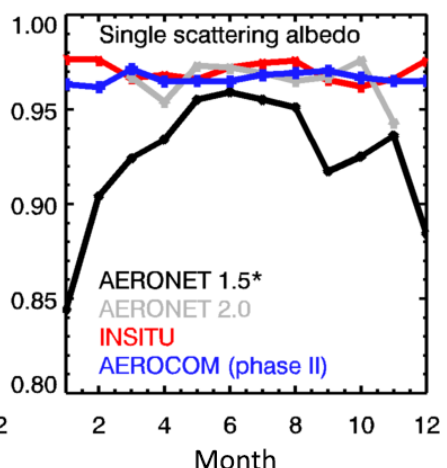

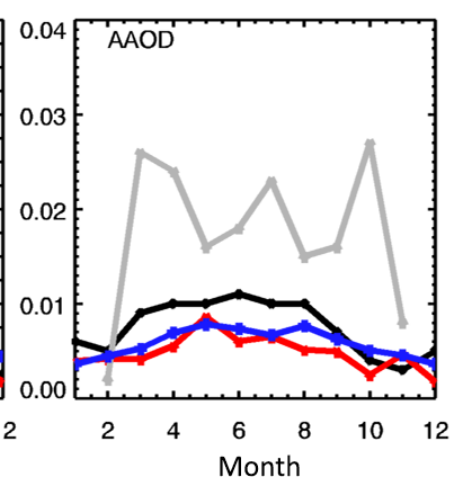

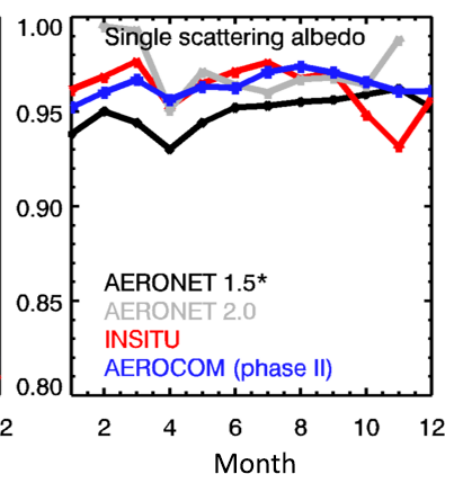

Figure 8. (a) Monthly medians of BND aerosol optical properties at $440 \mathrm{~nm}$. AERONET medians are for 1996-2011. AERONET AOD medians are for observations with Level 2 almucantar retrievals, with corresponding AAOD and SSA retrievals at Level 1.5 (black) or Level 2 (gray). In situ data are for June 2006-September 2009. AERONET Level 2.0 almucantar AOD and AAOD values are biased high by definition because of the $\mathrm{AOD}_{440}>0.4$ constraint. AERONET 2.0 direct-sun retrievals (not shown) are similar to the AERONET 1.5 AOD values. In situ values are derived from 365 flights over BND. AeroCom Phase II median model results cover various time periods (depending on the model) and are reported at $550 \mathrm{~nm}$. (b) Monthly medians of SGP aerosol optical properties at $440 \mathrm{~nm}$. AERONET medians are for 1996-2011. In situ data are for September 2005-December 2007. AERONET AOD medians are for observations with Level 2 almucantar retrievals, with corresponding AAOD and SSA retrievals at Level 1.5 (black) or Level 2 (gray). AERONET Level 2.0 almucantar AOD and AAOD values are biased high by definition because of the $\mathrm{AOD}_{440}>0.4$ constraint. AERONET 2.0 direct-sun retrievals (not shown) are similar to the AERONET 1.5 AOD values. In situ values are derived from 322 flights over SGP. AeroCom Phase II median model results cover various time periods (depending on the model) and are reported at $550 \mathrm{~nm}$.

al. (2011) and Fig. 9 in Sheridan et al. (2012) demonstrate that the BND and SGP flight programs captured the multiyear seasonality in aerosol properties at these two sites. Because of the large number of flights over an extended period of time, Skeie et al. (2011) were able to compare the seasonally averaged, in situ absorbing aerosol profiles from BND and SGP with seasonal vertical profiles of black carbon generated by the Oslo-CTM2 model. Skeie et al. (2011) found that the model underestimated absorbing aerosol relative to the BND and SGP in situ profiles for most seasons and altitudes, although agreement between the model and measurements tended to be better at higher altitudes.

As mentioned in the introduction, AERONET retrievals of AAOD have been used to suggest upscaling factors for modeled values of absorbing aerosol (e.g., Sato et al., 2003; Bond et al., 2013). These model-AERONET comparison studies are typically based on model and measurement statistics (i.e., properties are averaged over time and region) rather than direct comparisons due to both computational constraints and the discrete nature of the AERONET measurements. Given the statistical nature of some historical AERONETin situ comparisons as well as the typical model-AERONET comparison constraints, in this section we compare monthly statistics for in situ measurements, AERONET retrievals and AeroCom model output. It should be reiterated here that we are comparing asynchronous data and that there are some additional differences amongst the data sets that need to be kept in mind: the AERONET data are rigorously cloud-screened (although cloud halo effects may persist; e.g., Jeong and Li, 2010) and only obtained during daytime; the in situ measurements are also daytime-only and the airplane did not fly in clouds due to FAA flight restrictions but may have flown near clouds; and the model data include day and night with clouds and also represent values over a $1 \times 1^{\circ}$ grid.

Figure 8 shows the $440 \mathrm{~nm}$ monthly medians of AOD, AAOD and SSA at BND and SGP based on the in situ profile 
measurements and two versions of AERONET retrievals as described below. For the in situ properties, all profiles were used, regardless of whether there was an AERONET retrieval corresponding to the flight. The AERONET monthly medians in Fig. 8 use the long-term (1996-2013) AERONET data record for each site. As described previously, the lines labeled AERONET $1.5^{*}$ were calculated from Level 1.5 inversion data with matching Level 2 almucantar retrievals. The lines labeled AERONET 2.0 utilized only Level 2 almucantar retrieval data. In both cases the median AERONET AOD values represent those Level 2 AOD measurements for which there was also an AAOD and SSA retrieval, ensuring that the AERONET AOD medians represent the same set of retrievals as the corresponding AAOD and SSA medians in the figure. The AERONET Level 1.5* AOD monthly medians are representative of the direct-sun AERONET Level 2 AOD climatology at the two sites. Figure 8 also includes the AeroCom Phase II model monthly medians for BND and SGP (Kinne et al., 2006; Myhre et al., 2013) with model emissions, meteorology and other details briefly described in Myhre et al. (2013). The AeroCom values, which were provided at $550 \mathrm{~nm}$, have been adjusted to $440 \mathrm{~nm}$ using the reported AeroCom monthly scattering Ångström exponent to adjust AOD wavelength and assuming an absorption Ångström exponent of 1 for the AAOD wavelength adjustment. It should be noted that the three monthly data sets (AERONET, AeroCom and in situ) plotted in Fig. 8 are derived from measurements for overlapping, but not identical, time periods; i.e., these plots represent climatological comparisons rather than direct comparisons of the data sets.

At both sites, the climatological seasonal patterns for AOD (i.e., high in summer, low in winter) are similar for the three data sets: in situ measurements, AERONET Level $1.5^{*}$ retrievals (recall that the AERONET $1.5^{*}$ AOD is representative of the overall AERONET AOD climatology at each site) and AeroCom model output. At BND the AeroCom model AOD tends to be larger than the in situ and AERONET 1.5* AOD values by up to a factor of 2 . AERONET $1.5^{*}$ AOD is larger than the in situ AOD in the summer (by up to $50 \%$ ) but quite close the rest of the year (typically within $20 \%$ ). While a $50 \%$ discrepancy between the AERONET and in situ climatology may appear significant, it is important to remember that these data sets do not represent the same period of time or measurement conditions (e.g., time of day, cloud cover, aerosol events, ambient humidity). Schutgens et al. (2016) show there can be large differences when comparing values obtained with different samplings (more than $100 \%$ for AOD), particularly when there are high levels of variability in the data. At SGP the AOD monthly medians from in situ measurements and AERONET Level 1.5* are almost identical for August-December, with slightly more discrepancy among the AOD values in summer and early part of the year. In contrast, AeroCom model median AOD values tend to agree better with AERONET $1.5^{*}$ and in situ AOD values from January to July but are noticeably higher (up to a factor of 2) in the later half of the year. At both sites, the median AERONET Level 2 AOD values (corresponding to AAOD and SSA retrievals) are much higher (by a factor of 2 or more) than the Level $1.5^{*}$ and in situ climatologies due to the $\mathrm{AOD}_{440}>0.4$ constraint. During the cleanest, lowest humidity, and often cloudiest months of the year (DecemberFebruary) there are none to few Level 2 almucantar retrievals of SSA and AAOD at either BND or SGP - the gray lines in Fig. 8a and $\mathrm{b}$ are lacking data points for January, February and December at BND and January and December at SGP.

For AAOD at BND, the AeroCom model output falls between the AERONET $1.5^{*}$ and in situ values, with AERONET 1.5* AAOD being higher than the in situ data by up to a factor of 8 . As with AOD, the AERONET AAOD Level 2 values are much higher than the in situ or modeled AOD values due to the constraint that they are only retrieved at high loading conditions $\left(\mathrm{AOD}_{440}>0.4\right)$. The three data sets (AeroCom, in situ and AERONET $1.5^{*}$ ) agree best in the month of May when the median values of AAOD are within $30 \%$. At SGP there is fairly good agreement between AeroCom model and in situ AAOD for the first 7 months of the year, while the AERONET $1.5^{*}$ monthly AAOD values are considerably higher for that same time period. For the latter part of the year the in situ AAOD values tend to be lower than both AERONET and AeroCom AAOD values.

The AERONET 1.5* SSA values tend to be quite a bit lower at BND, and somewhat lower at SGP, which is why the AERONET 1.5* AAOD values tend to be higher (recall that for AERONET data AAOD is calculated using $\mathrm{AAOD}=(1-\mathrm{SSA}) \times \mathrm{AOD})$. Figure 8 also shows that the AERONET Level 2 SSA values are similar to the monthly in situ and AeroCom SSA medians between April and November. There are no AERONET Level 2 almucantar retrievals of SSA in January or December at either site. For the February and March, median Level 2 almucantar retrievals of SSA are based on very few data points, resulting in bigger discrepancies between AERONET Level 2 almucantar retrievals of SSA and the in situ and AeroCom SSA values.

Aside from differences in magnitude, there are also differences in the seasonal patterns of AOD, AAOD and SSA for the three data sets (in situ, AERONET $1.5^{*}$ and AeroCom). For example, at BND, the AERONET and in situ AAOD both have a bi-modal annual distribution with peaks in late spring and early fall, which is not captured by the AeroCom AAOD and which is not seen in the AOD seasonality. The observed seasonal differences may be a result of (a) the different climatology time ranges for each method and/or (b) very little overlap in the measurement times for AERONET and in situ measurements or (c), in the case of the models, not capturing local emissions near the sites. This highlights the importance of direct (i.e., near in time and space) comparisons in order to understand these seasonal differences. The seasonal cycle plots in Fig. 8 also direct attention to the fact that AOD and AAOD vary independently rather than exhibiting the same seasonal pattern. This suggests that different emis- 
sion sources and/or atmospheric processes control the variability of absorption and scattering aerosol over the course of the year.

\subsection{Discussion}

Because AERONET data are readily available and are being widely used as a benchmark data set for evaluating model output of AAOD (e.g., Chung et al., 2012; Bond et al., 2013; He et al., 2014; Wang et al., 2014) as well as for comparison with satellite retrievals and development of AAOD climatologies, we document and discuss some of the previous methods for utilizing existing AERONET retrievals that have been used to estimate AAOD at low AOD $\left(\mathrm{AOD}_{440}<0.4\right)$ where Level 2 retrievals do not exist. These approaches fall into several categories: (1) use only Level 2 data; (2) use Level 2 and Level 1.5 data with acknowledgement of greater uncertainty in the retrievals and potentially additional measurement constraints for the Level 1.5 data; (3) make climatological assumptions about the representativeness of Level 2 SSA for low-AOD conditions to obtain AAOD.

Clearly the simplest approach to minimize uncertainty in retrieved AERONET AAOD and SSA is to only use AERONET Level 2 retrievals which include the $\mathrm{AOD}_{440}>0.4$ constraint. This approach has been and continues to be used (e.g., Koch et al., 2009; Bahadur et al., 2010; Chung et al., 2012; Buchard et al., 2015; Pan et al., 2015; Li et al., 2015). However, as shown in Fig. 1 the vast majority of the globe has $\mathrm{AOD}_{440}<0.4$, meaning few if any AERONET Level 2 AAOD or SSA retrievals will be available for most locations. This approach is quite useful in regions (or for case studies) with high aerosol loading (high AOD). However, excluding low-loading conditions is likely to cause AERONET AAOD statistics to be biased high. This is particularly important when evaluating models in clean locations such as the Arctic. The $\mathrm{AOD}_{440}>0.4$ constraint may also affect the SSA statistics.

Some studies have utilized AERONET Level 1.5 retrievals of absorption-related aerosol properties in order to avoid being limited to the high AOD levels required by Level 2 data (e.g., Lacagnina et al., 2015; Mallet et al., 2013). These studies note that Level 1.5 data include more relevant AOD values but that there are accompanying higher uncertainties in the retrievals for absorption-related properties. Mallet et al. (2013) use Level 1.5 data to evaluate the spectral dependence of aerosol absorption. Lacagnina et al. (2015) utilize both Level 2 and Level 1.5 AERONET data in their comparison with PARASOL satellite retrievals of SSA and AAOD. For the Level 1.5 data they apply the additional requirement that the solar zenith angle must be $\geq 50^{\circ}$. Lacagnina et al. (2015) find quite good agreement (within \pm 0.03 ) for AAOD and note that larger differences between PARASOL and AERONET retrieval occur at higher AOD conditions, possibly due to less-homogenous aerosol (i.e., plumes).
A more sophisticated approach to deal with SSA (and hence AAOD uncertainties) at low AOD is implemented by Wang et al. (2014). They make the assumption that SSA is independent of AOD (at least as a function of season) and utilize climatological Level 2 SSA values for each season with the measured AOD in order to obtain AAOD. The seasonal climatologies of SSA are based on 12 years of Level 2 AERONET data. For the two US continental sites studied in this paper, the approach of Wang et al. (2014) would likely minimize the potential AERONET tendency towards high AAOD at low-AOD conditions as the Level 2 monthly climatological SSA values are quite similar to SSA values obtained by in situ measurements (Fig. 8).

A similar, though statistical, approach was used in the bounding BC paper by Bond et al. (2013) in order to reduce the uncertainty and better represent AERONET SSA and AAOD retrievals at low AOD. Bond et al. (2013) worked with AERONET monthly local statistics for the time period 2000-2010. Monthly values of AAOD and SSA at $550 \mathrm{~nm}$ were calculated from size distributions and refractive index when there were at least 10 valid inversion retrievals for that month at that site in the 2000-2010 period (most sites had more than 10 retrievals in a given month over the 11-year period). It was assumed in Bond et al. (2013), based on AERONET reported uncertainties, that the retrieved absorption-related values were more reliable at larger AOD and so they made some adjustments to account for this. For each site, AAOD and SSA values were binned as a function of AOD (there were five AOD bins, with each bin corresponding to $20 \%$ of the AOD probability distribution). For lower AOD conditions, the calculated AAOD and SSA values were replaced by values obtained during larger AOD conditions for the same month as follows: (i) the SSA and AAOD values corresponding to $\mathrm{AOD}_{550}$ of 0.25 were prescribed for all SSA and AAOD observations at lower AOD and (ii), for locations where all $\mathrm{AOD}_{550}<0.25$, the average SSA and AAOD of the upper 20th percentile of AOD observations at the site was prescribed for all lower AOD bins. Finally, the average of all five bins was used to determine the overall monthly average. In the case of AAOD the bin averages were simply averaged to get the monthly value while for SSA the AOD-weighted bin averages were averaged to get the monthly value. Note: the $\mathrm{AOD}_{550}=0.25$ cutoff point used in Bond et al. (2013) corresponds (approximately) to $\mathrm{AOD}_{440}=0.35$ for smaller particles and $\mathrm{AOD}_{440}=0.25$ when large particles are present. Thus it is less strict than the AERONET recommended constraint of $\mathrm{AOD}_{440}>0.4$, but it had been suggested that the recommended constraint might be too restrictive (O. Dubovik, personal communication, 2017).

One drawback affecting approaches using climatological values of SSA (e.g., Wang et al., 2014; Bond et al., 2013) is that they may not account for the systematic variability that has been observed between SSA and loading at many sites, although AOD is usually more variable than the com- 

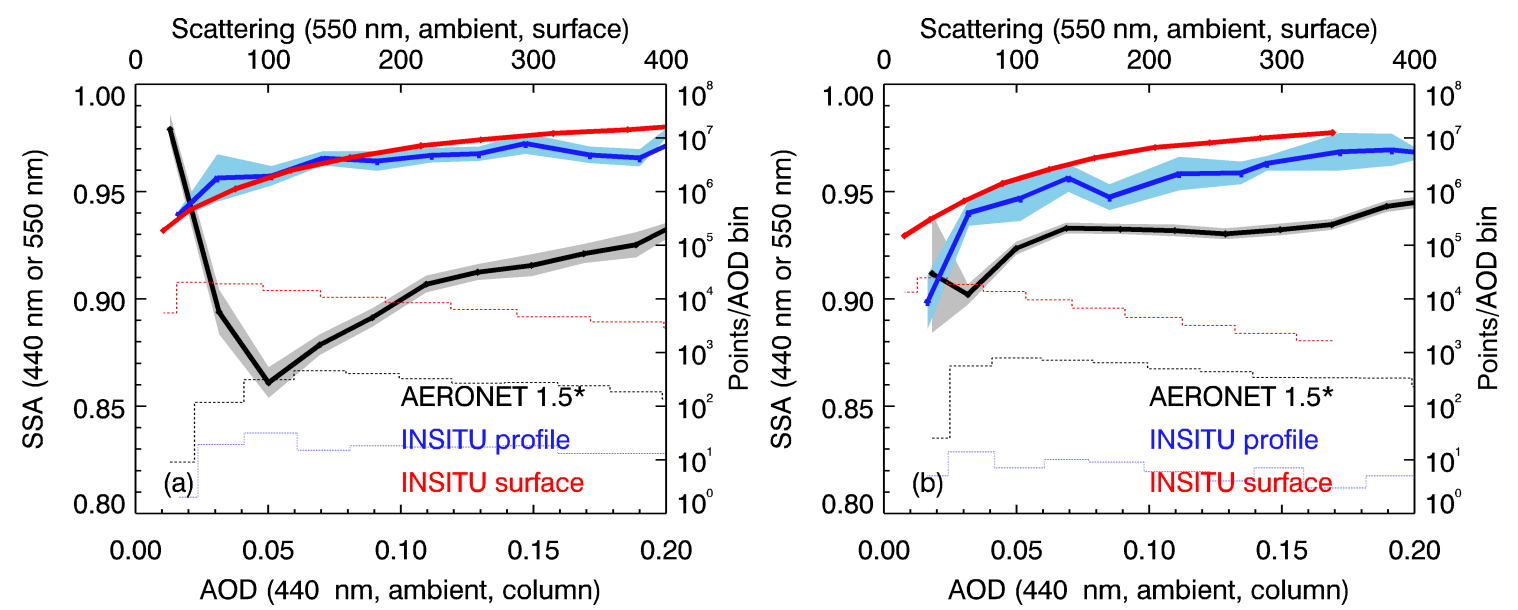

Figure 9. Systematic variability of SSA as a function of loading for (a) BND and (b) SGP for AERONET 1.5* AOD and SSA (black lines), AOD and SSA from in situ profiles (blue lines) and in situ scattering and SSA from surface measurements (red lines). Solid lines indicate mean values of SSA and AOD for each 0.05 AOD bin $\left(10 \mathrm{Mm}^{-1}\right.$ scattering bin). Shaded areas represent mean standard error (mean standard error for surface data is within thickness of red line). Histograms indicate the number of points in each AOD (or scattering) bin. Plot based on BND and SGP AERONET data (date range: 1996-2012), BND INSITU profile data (date range: 2006-2012) and SGP INSITU profile data (date range: 2006-2007). Surface data (orange lines) are for $550 \mathrm{~nm}$, low-RH, hourly in situ data from the surface sites at BND (date range: 1997-2013) and SGP (date range: 1998-2013). AERONET 1.5* is from Level 1.5 retrievals with a corresponding Level 2 almucantar retrieval.

position (or SSA). Still some studies with in situ data (e.g., Delene and Ogren, 2002; Andrews et al., 2013; Pandolfi et al., 2014; Sherman et al., 2015) indicate that SSA systematically decreases with decreasing aerosol loading. A similar SSA/AOD systematic variability relationship is also observed at some North American AERONET sites. Schafer et al. (2014; their Fig. 6) show SSA decreasing at lower loading for the GSFC site near Washington DC during the period of their field campaign; they also show similar relationships between SSA and AOD based on the long-term data for three mid-Atlantic AERONET sites. Additionally, a quick survey (not shown) of other long-term North American AERONET sites with good statistics (i.e., lots of points) for Level 1.5 SSA retrievals (e.g., Billerica (Massachusetts), Bratt's Lake (Saskatchewan, Canada), COVE (Virginia), Egbert (Ontario, Canada), Fresno (California), Konza (Kansas), SERC (Maryland) and University of Houston (Texas)) indicates this systematic relationship may be observed at a wide range of locations in North America. Such climatological analyses may mask short-lived and/or infrequent aerosol events (e.g., dust or smoke incursions) that may have significantly different optical properties.

Figure 9 shows the systematic relationships between $\mathrm{SSA}_{440}$ and $\mathrm{AOD}_{440}$ for BND and SGP for both the AERONET retrievals and in situ profile measurements. Consistent with previous figures, we have utilized SSA values for $\mathrm{AOD}_{440}<0.4$ when there was a valid Level 2 AOD inversion retrieval, i.e., what we call AERONET Level 1.5*. Also included on the figure is a line showing the $\mathrm{SSA}_{550}$ versus scattering $\left(\sigma_{\mathrm{sp}, 550}\right)$ relationships for the surface measure- ments at BND and SGP. The surface measurements are made at low $\mathrm{RH}$ conditions $(\mathrm{RH}<40 \%)$ and adjusted to ambient $\mathrm{RH}$ using the available meteorological measurements at the site (ambient RH at $2 \mathrm{~m}$ at SGP and ambient RH at $10 \mathrm{~m}$ at BND); adjustment of the surface measurements from dry to ambient conditions shifts the $\mathrm{SSA}_{550}$ values upward (assuming absorption is not affected) and the scattering values to the right.

Figure 9 suggests that for all three sets of measurements at both sites, there is a consistent decrease in SSA as aerosol loading decreases below $\mathrm{AOD}_{440}=0.2$. This relationship implies that a climatology based on SSA values measured at high AOD may underestimate the AAOD climatology. The AERONET SSA values are lower than the in situ profile values as would be expected from the results presented in Sect. 3.1 and 3.3. The AERONET SSA values are also lower than the surface in situ SSA values - the surface in situ SSA values adjusted to ambient conditions are quite similar to those obtained from the in situ vertical profiles. It should, however, be noted that despite the discrepancy between in situ and AERONET SSA values, Fig. 9 shows that the SSA values for all three sets of measurements at SGP are within the reported AERONET SSA uncertainty range of $0.05-0.07$ for $\mathrm{AOD}_{440}<0.2$ across the narrow and lowAOD range shown in the figure. At BND the SSA values are within the AERONET SSA uncertainty range down to $\mathrm{AOD}_{440} \sim 0.1$. At the lowest AOD values $\left(\mathrm{AOD}_{440}<\sim 0.05\right)$ the AERONET SSA values diverge, consistent with very large uncertainties expected in the AERONET SSA retrievals in the cleanest conditions. Uncertainty in the AERONET 
AOD retrieval may begin to affect the AERONET SSA retrieval where \pm 0.01 AOD uncertainty is equivalent to a $20 \%$ change in AOD for AOD of 0.05. In addition, at such lowAOD values, the surface reflectance uncertainties may influence AERONET's retrieval of SSA. Figure 9 suggests that, in terms of the shape of the systematic variability plot, there are no obvious retrieval issues for AERONET SSA retrievals in the range $0.05<\mathrm{AOD}_{440}<0.2$, although this is in the $\mathrm{AOD}$ range where high uncertainty in the SSA retrieval is expected (Dubovik et al., 2000).

There are large differences (orders of magnitude) in the number of data points in each of the data sets; the number of points in each bin is indicated by the color-coded histograms shown on Fig. 9. The mean standard error (MSE) in SSA $\left(\mathrm{MSE}=(\right.$ standard deviation $\left.) /(\text { number of points })^{1 / 2}\right)$ is indicated by the shading surrounding the solid colored lines. The MSE is quite similar for the AERONET $1.5^{*}$ and in situ profile measurements across the AOD range plotted in Fig. 9, suggesting the observed systematic variability is not merely due to small numbers of data points in each bin, particularly at lower loading. However, the fact that the AERONET MSE is approximately the same as the in situ profile MSE, despite having approximately an order of magnitude larger number of points/bin, indicates that variability in the retrieved AERONET SSA is larger than the variability in SSA derived from in situ profile measurements.

This study has utilized a valuable but spatially limited (i.e., two rural continental North American sites) climatological vertical profile data set to explore AERONET retrievals of AAOD and SSA. Clearly, one way to address the observed discrepancy between in situ and AERONET AAOD is to pursue a focused measurement program designed to acquire statistically robust in situ vertical profiles over AERONET sites representing a wide range of conditions and aerosol types. This type of measurement program has been proposed to evaluate satellite retrievals and better characterize atmospheric aerosol (R. Kahn, personal communication, 2016). Further evaluation and development of in situ instrumentation for measuring aerosol absorption is also necessary, particularly in assessing the effects of coatings and hygroscopicity on the resulting absorption values. Additional evaluation of the AERONET retrieval algorithm may provide insight into a potential SSA and, thus, AAOD bias (e.g., Hashimoto et al., 2012). The discrepancies reported here between in situ and AERONET values of AAOD and SSA suggest that caution should be used in upscaling model results to match AERONET retrievals of absorbing aerosol as this will have a significant impact on global radiative forcing estimates. The work of Wang et al. (2016) has shown that other factors (e.g., the spatial resolution of models and emissions) may also contribute to the differences observed between model and AERONET retrievals of AAOD. Thus, really being able to understand and simulate the influence of absorbing aerosol on radiative forcing will require expanded effort on both the measurement and modeling fronts.

\section{Conclusions}

AERONET retrievals of SSA at low-AOD conditions (below the recommended $\mathrm{AOD}_{440}<0.4$ constraint) are consistently lower than coincident and co-located in situ vertical profile observations of SSA (based on detailed comparisons at two rural sites in the US). Correspondingly, AERONET retrievals of AAOD at low AOD are consistently higher than those obtained from in situ profiles. A survey of the literature suggests that even at higher loading $\left(\mathrm{AOD}_{440}>0.4\right)$ AERONET SSA retrievals tend to be lower than SSA values obtained from vertical profiling flights, although discrepancies are within the reported uncertainty bounds down to $\sim \mathrm{AOD}_{440}>0.3$. The tendency of AERONET SSA to be lower suggests either that AERONET retrievals overestimate absorbing aerosol or that the in situ measurements underestimate aerosol absorption. Since the observed discrepancy in SSA cannot definitively be attributed to either technique, the idea of scaling modeled black carbon concentrations upwards to match AERONET retrievals of AAOD should be approached with caution. If the AERONET SSA and AAOD retrievals are indeed biased towards higher absorption, such an upscaling may lead to aerosol absorption overestimates, particularly in regions of low AOD. If the discrepancy between the in situ and AERONET AAOD is due to issues with the in situ measurements of absorption, the only way we see to increase the in situ absorption values is a significant enhancement (on the order of a factor of 2 or more) in absorption due to a coating effect. While that level of absorption enhancement factor is within the range suggested by modeling studies, it is significantly higher than many observations of absorption enhancement for ambient aerosol reported in the literature.

The AERONET retrievals of SSA and AAOD have been used as a primary constraint on global model simulations of aerosol absorption. Using only Level 2 retrievals of AAOD (i.e., for $\mathrm{AOD}_{440}>0.4$ ) on a global scale (e.g., Koch et al., 2009; Bahadur et al., 2010; Chung et al., 2012; Buchard et al., 2015; Pan et al., 2015; Li et al., 2015) is likely to lead to significant overestimates of absorption in cleaner regions although it may be appropriate for conditions of high loading. Several different approaches of varying complexity have been developed to better represent absorbing aerosol for cleaner conditions. Some of these approaches utilize SSA at high AOD to estimate AAOD at lower AOD conditions (e.g., Bond et al., 2013; Wang et al., 2014), while others utilize Level 1.5 retrievals with the added uncertainty that entails (e.g., Lacagnina et al., 2015; Mallet et al., 2013). Based on the analysis presented here, we cannot say how to best estimate SSA or AAOD from AERONET retrievals for the lowAOD conditions prevalent around much of the globe.

Some in situ measurements suggest that a systematic relationship exists between SSA and AOD, but these measurements are spatially sparse and typically not made at ambient conditions. Nonetheless, systematic relationships be- 
tween SSA and AOD, similar to those seen in the in situ data at the two sites, are also observed for multiple North American AERONET sites. The existence of such a systematic relationship may limit the accuracy of AAOD estimates when climatological values for SSA from high-AOD retrievals are assumed to apply at low-loading conditions. However, for the two mid-continental rural sites studied here, the statistically based monthly medians of SSA from Level 2.0 inversions (i.e., SSA values derived for $\mathrm{AOD}_{440}>0.4$ ) appear to be quite consistent with monthly SSA values obtained from in situ measurements and AEROCOM model simulations. This suggests that, at these two sites, using the Level 2.0 inversion SSA to retrieve monthly AAOD at lower AOD conditions (e.g., $\mathrm{AAOD}=\mathrm{AOD} \times \mathrm{SSA}$ ) would not bias the resulting monthly AAOD high, as would occur if only AAOD values for high-AOD cases are included in the AAOD statistics. This may not be true for other locations or averaging times. Further, for these two sites, a more complex approach to retrieve monthly AAOD is needed for very clean months when no Level 2.0 inversions are available.

This study points to several areas where additional research would be useful in resolving the observed AERONET-in situ absorption-related discrepancies. First, continued laboratory, field and modeling efforts are needed to elucidate and unify the current inconsistencies in the literature on the effects of coatings on absorption enhancement reported for field and lab measurements and for model simulations. Second, a more extensive evaluation of the hygroscopicity of ambient (not lab-generated!) absorbing particles would be helpful. Third, better characterization of how filterbased measurements of absorption respond to coated particles would be useful, not just in the context of this study but also for improving our understanding of the in situ absorption data acquired by long-term surface aerosol monitoring networks (e.g., GAW). Finally, the development of a focused measurement program designed to acquire statistically robust in situ vertical profiles over AERONET sites representing a wide range of conditions and aerosol types could be used to explore the relationships between retrievals of column properties and variable aerosol profiles and to provide further validation of the inversion retrieval data products.

Data availability. AERONET Direct sun AOD for Bondville (BND) are available here: https://aeronet.gsfc.nasa.gov/cgi-bin/ webtool_opera_v2_new?stage=3\&region=United_States_ Central\&state=Illinois\&site=BONDVILLE\&place_code $=10$; AERONET Direct sun AOD for Southern Great Plains (SGP) are available here: https://aeronet.gsfc.nasa.gov/cgi-bin/webtool_ opera_v2_new?stage=3\&region=United_States_Central\&state= Oklahoma\&site=Cart_Site\&place_code $=10$; AERONET inversion data (e.g., SSA, AAOD, size distribution) for BND are available here: https://aeronet.gsfc.nasa.gov/cgi-bin/webtool_opera_v2_ inv?stage=3\&region=United_States_Central\&state=Illinois\&site= BONDVILLE\&place_code=10\&if_polarized=0; AERONET inversion data (e.g., SSA, AAOD, size distribution) for SGP are available here: https://aeronet.gsfc.nasa.gov/cgi-bin/webtool_opera_v2_inv? stage $=3 \&$ region $=$ United_States_Central\&state=Oklahoma\&site= Cart_Site\&place_code $=10 \&$ if_polarized $=0 ;$ BND aircraft data are available here: ftp://aftp.cmdl.noaa.gov/aerosol/aao/; SGP aircraft data are available here: http://www.archive.arm.gov/discovery/v/ datastreams/s/streams:sgpiapavgC1.

Acknowledgements. Funding for the SGP airplane measurements was provided by DOE/ARM, while the BND airplane measurements were funded by NOAA's Climate Program Office. Greenwood Aviation and FlightSTAR provided fabulous pilots and maintenance of the aircraft. Derek Hageman (University of Colorado) is owed much for his coding genius and Patrick Sheridan (NOAA/ESRL/GMD) for making instruments on both airplanes work and ensuring the quality of the BND aircraft data set. We thank the modeling groups for providing AeroCom Phase II results. We greatly appreciate the ease of access to and use of IMPROVE aerosol chemistry data for the Bondville and Cherokee Nation IMPROVE sites. IMPROVE data were downloaded from: http://views.cira.colostate.edu/web/DataWizard/. This study was supported by NOAA Climate Program Office's Atmospheric Chemistry, Carbon Cycle and Climate (AC4) program. BHS acknowledges funding by the Research Council of Norway through the grants AC/BC (240372) and NetBC (244141). Last, but not least, we also gratefully acknowledge the very helpful discussions from David Giles and Brent Holben from AERONET and the very useful and extensive comments from our reviewers.

Edited by: S. Kazadzis

Reviewed by: three anonymous referees

\section{References}

Adam, M., Putaud, J. P., Martins dos Santos, S., Dell'Acqua, A., and Gruening, C.: Aerosol hygroscopicity at a regional background site (Ispra) in Northern Italy, Atmos. Chem. Phys., 12, 57035717, doi:10.5194/acp-12-5703-2012, 2012.

Anderson, T. L., Charlson, R. J., Winker, D. M., Ogren, J. A., and Holmén, K.: Mesoscale Variations of Tropospheric Aerosols, J. Atmos. Sci., 60, 119-136, 2003.

Anderson, T. L. and Ogren, J. A.: Determining aerosol radiative properties using the TSI 3563 integrating nephelometer, Aerosol Sci. Tech., 29, 57-69, 1998.

Andreae, M. O. and Gelencsér, A.: Black carbon or brown carbon? The nature of light-absorbing carbonaceous aerosols, Atmos. Chem. Phys., 6, 3131-3148, doi:10.5194/acp-6-3131-2006, 2006.

Andrews, E., Sheridan, P. J., and Ogren, J. A.: Seasonal differences in the vertical profiles of aerosol optical properties over rural Oklahoma, Atmos. Chem. Phys., 11, 10661-10676, doi:10.5194/acp-11-10661-2011, 2011.

Andrews, E., Ogren, J. A., Bonasoni, P., Marinoni, A., Cuevas, E., Rodriquz, S., Sun, J. Y., Jaffe, D. A., Fischer, E. V., Baltensperger, U., Weingartner, E., Collaud Coen, M., Sharma, S., Macdonald, A. M., Leaitch, W. R., Lin, N.-H., Laj, P., Arsov, T., Kalapov, I., Jefferson, A., and Sheridan, P.,: Climatology of 
aerosol radiative properties in the free troposphere, Atmos. Res., 102, 365-393, 2011b.

Arnott, W. P., Hamasha, K., Moosmuller, H., Sheridan, P. J., and Ogren, J. A.: Towards aerosol light-absorption measurements with a 7-wavelength aethalometer: evaluation with a photoacoustic instrument and 3-wavelength Nephelometer, Aerosol Sci. Tech., 39, 17-29, 2005.

Bahadur, R., Praveen, P. S., Xu, Y., and Ramanathan, V.: Solar absorption by elemental and brown carbon determined from spectral observations, P. Natl. Acad. Sci. USA, 109, 17366-17371, doi:10.1073/pnas.1205910109, 2012.

Bergin, M. H., Ogren, J. A., Schwarz, S. E., and McInnes, L. M.: Evaporation of Ammonium Nitrate Aerosol in a Heated Nephelometer: Implications for field measurements, Environ. Sci. Technol., 31, 2878-2883, 1997.

BIPM: Evaluation of measurement data - Guide to the expression of uncertainty in measurement, Joint committee for guides in metrology (JCGM): 100, http://www.iso.org/sites/ JCGM/GUM-JCGM100.htm (last access: 22 May 2015), 2008.

Bond, T. C., Anderson, T. L., and Campbell, D.: Calibration and intercomparison of filter-based measurements of visible light absorption by aerosols, Aerosol Sci. Tech., 30, 582-600, doi:10.1080/027868299304435, 1999.

Bond, T. C., Doherty, S. J., Fahey, D. W., Forster, P. M., Berntsen, T., DeAngelo, B. J., Flanner, M. G., Ghan, S., Kärcher, B., Koch, D., Kinne, S., Kondo, Y., Quinn, P. K., Sarofim, M. C., Schultz, M. G., Schulz, M., Venkataraman, C., Zhang, H., Zhang, S., Bellouin, N., Guttikunda, K., Hopke, P. K., Jacobson, M. Z., Kaiser, J. W., Klimont, Z., Lohmann, U., Scwarz, J. P., Shindell, D., Storelvmo, T., Warren, S. G., and Zender, C. S.: Bounding the role of black carbon in the climate system: A scientific assessment, J. Geophys. Res., 118, 5380-5552, doi:10.1002/jgrd.50171, 2013.

Bond, T. C., Habib, G., and Bergstrom, R. W.: Limitations in the enhancement of visible light absorption due tomixing state, J. Geophys. Res., 111, D20211, doi:10.1029/2006JD007315, 2006.

Brem, B. T., Mena Gonzalez, F. C., Meyers, S. R., Bond, T. C., and Rood, M. J.: Laboratory-Measured Optical Properties of Inorganic and Organic Aerosols at Relative Humidities up to $95 \%$, Aerosol Sci. Tech., 46, 178-190, 2012.

Buchard, V., da Silva, A. M., Colarco, P. R., Darmenov, A., Randles, C. A., Govindaraju, R., Torres, O., Campbell, J., and Spurr, R.: Using the OMI aerosol index and absorption aerosol optical depth to evaluate the NASA MERRA Aerosol Reanalysis, Atmos. Chem. Phys., 15, 5743-5760, doi:10.5194/acp-15-57432015, 2015.

Burrows, J. P., Dehn, A., Deters, B., Himmelmann, S., Richter, A., Voigt, S. and Orphal, J.: Atmospheric Remote-Sensing Reference Data from GOME: Part 1. Temperature-Dependent Absorption Cross-sections of $\mathrm{NO}_{2}$ in the 231-794 nm Range, JQSRT, 60, 1025-1031, 1998.

Carrico, C. M., Kus, P., Rood, M. J., Quinn, P. K., and Bates, T. S.: Mixtures of pollution, dust, sea salt and volcanic aerosol during ACE-Asia: Radiative properties as a function of relative humidity, J. Geophys. Res., 108, 8650, doi:10.1029/2003JD003405, 2003.

Cappa, C. D., Onasch, T. B., Massoli, P., Worsnop, D. R., Bates, T. S., Cross, E. S., Davidovits, P., Hakala, J., Hayden, K. L., Jobson, B. T., Kolesar, K. R., Lack, D. A., Lerner, B. M., Li, S.-M., Mel- lon, D., Nuaaman, I., Olfert, J. S., Petäjä, T., Quinn, P. K., Song, C., Subramanian, R., Williams, E. J., Zaveri, R. A.: Radiative absorption enhancements due to the mixing state of atmospheric black carbon, Science, 337, 1078-1081, 2012.

Chin, M. T., Diehl, T., Dubovik, O., Eck, T. F., Holben, B. N., Sinyuk, A., and Streets, D. G.: Light absorption by pollution, dust, and biomass burning aerosols: a global model study and evaluation with AERONET measurements, Ann. Geophys., 27, 3439-3464, 2009.

Chung, C., Ramanathan, V., and Decremer, D.: Observationally constrained estimates of carbonaceous aerosol radiative forcing, PNAS, 109, 11624-11629, 2012.

Corr, C. A., Krotkov, N., Madronich, S., Slusser, J. R., Holben, B., Gao, W., Flynn, J., Lefer, B., and Kreidenweis, S. M.: Retrieval of aerosol single scattering albedo at ultraviolet wavelengths at the T1 site during MILAGRO, Atmos. Chem. Phys., 9, 58135827, doi:10.5194/acp-9-5813-2009, 2009.

Corrigan, C. E., Roberts, G. C., Ramana, M. V., Kim, D., and Ramanathan, V.: Capturing vertical profiles of aerosols and black carbon over the Indian Ocean using autonomous unmanned aerial vehicles, Atmos. Chem. Phys., 8, 737-747, doi:10.5194/acp-8-737-2008, 2008.

Crumeyrolle, S., Chen, G., Ziemba, L., Beyersdorf, A., Thornhill, L., Winstead, E., Moore, R. H., Shook, M. A., Hudgins, C., and Anderson, B. E.: Factors that influence surface $\mathrm{PM}_{2.5}$ values inferred from satellite observations: perspective gained for the US Baltimore-Washington metropolitan area during DISCOVERAQ, Atmos. Chem. Phys., 14, 2139-2153, doi:10.5194/acp-142139-2014, 2014.

Delene, D. J. and Ogren, J. A.: Variability of aerosol optical properties at four North American surface monitoring sites, J. Atmos. Sci., 59, 1135-1150, 2002.

Doran, J. C., Barnard, J. C., Arnott, W. P., Cary, R., Coulter, R., Fast, J. D., Kassianov, E. I., Kleinman, L., Laulainen, N. S., Martin, T., Paredes-Miranda, G., Pekour, M. S., Shaw, W. J., Smith, D. F., Springston, S. R., and Yu, X.-Y.: The T1-T2 study: evolution of aerosol properties downwind of Mexico City, Atmos. Chem. Phys., 7, 1585-1598, doi:10.5194/acp-7-1585-2007, 2007.

Dubovik, O. and King, M. D.: A flexible inversion algorithm for retrieval of aerosol optical properties from Sun and sky radiance measurements, J. Geophys. Res., 105, 20673-20696, 2000.

Dubovik, O., Sinyuk, A., Lapyonok, T., Holben, B. N., Mishchenko, M., Yang, P., Eck, T. F., Volten, H., Munoz, O., Veihelmann, B., van der Zande, W. J., Leon, J.-F. ,Sorokin, M., and Slutsker, I.: Application of spheroid models to account for aerosol particle nonsphericity in remote sensing of desert dust, J. Geophys. Res., 111, D11208, doi:10.1029/2005JD006619, 2006.

Dubovik, O., Smirnov, A., Holben, B. N., King, M. D., Kaufman, Y. J., Eck, T. F., and Slutsker, I.: Accuracy assessment of aerosol optical properties retrieval from AERONET sun and sky radiance measurements, J. Geophys. Res., 105, 9791-9806, 2000.

Eck, T. F., Holben, B. N., Reid, J. S., Dubovik, O., Smirnov, A., O'Neill, N. T., Slutsker, I., and Kinne, S: Wavelength dependence of the optical depth of biomass burning, urban and desert dust aerosols, J. Geophys. Res., 104, 31333-31350, 1999.

Eck, T. F., Holben, B. N., Reid, J. S., Arola, A., Ferrare, R. A., Hostetler, C. A., Crumeyrolle, S. N., Berkoff, T. A., Welton, E. J., Lolli, S., Lyapustin, A., Wang, Y., Schafer, J. S., Giles, D. M., Anderson, B. E., Thornhill, K. L., Minnis, P., Pickering, K. E., 
Loughner, C. P., Smirnov, A., and Sinyuk, A.: Observations of rapid aerosol optical depth enhancements in the vicinity of polluted cumulus clouds, Atmos. Chem. Phys., 14, 11633-11656, doi:10.5194/acp-14-11633-2014, 2014.

Engelbrecht, J. P., Moosmüller, H., Pincock, S., Jayanty, R. K. M., Lersch, T., and Casuccio, G.: Technical note: Mineralogical, chemical, morphological, and optical interrelationships of mineral dust re-suspensions, Atmos. Chem. Phys., 16, 10809-10830, doi:10.5194/acp-16-10809-2016, 2016.

Esteve, A. R., Ogren, J. A., Sheridan, P. J., Andrews, E., Holben, B. N., and Utrillas, M. P.: Sources of discrepancy between aerosol optical depth obtained from AERONET and in-situ aircraft profiles, Atmos. Chem. Phys., 12, 2987-3003, doi:10.5194/acp-122987-2012, 2012.

Ferrero, L., Mocnik, G., Ferrini, B. S., Perrone, M. G., Sangiorgi, G., and Bolzacchini, E.: Vertical profiles of aerosol absorption coefficient from micro-aethalometer data and Mie calculation over Milan, Sci. Tot. Environ, 409, 2824-2837, 2011.

Formenti, P., Boucher, O., Reiner, T., Sprung, D., Andreae, M. O., Wendisch, M., Wex, H., Kindred, D., Tzortziou, M., Vasaras, A., and Zerefos, C.: STAAARTE-MED 1998 summer airborne measurements over the Aegean Sea, 2. Aerosol scattering and absorption, and radiative calculations, J. Geophys. Res., 107, 4451, doi:10.1029/2001JD001536, 2002.

Giles, D. M., Holben, B. N., Eck, T. F., Sinyuk, A., Smirnov, A., Slutsker, I., Dickerson, R. R., Thompson, A. M., and Schafer, J. S.: An analysis of AERONET aerosol absorption properties and classifications representative of aerosol source region, J. Geophys. Res., 117, D17203, doi:10.1029/2012JD018127, 2012.

Hamonou, E., Chazette, P., Balis, D., Schneider, X., Galani, E., Ancellet, G., and Papayannis, A.: Characterization of the vertical structure of Saharan dust export to the Mediterranean basin, J. Geophys. Res., 104, 22257-22270, 1999.

Hänel, G.: The properties of atmospheric aerosol particles as functions of the relative humidity at thermodynamic equilibrium with surrounding moist air, Adv. Geophys., 19, 73-188, 1976.

Hansen, J., Sato, M., and Ruedy, R.: Radiative forcing and climate response, J. Geophys. Res., 102, 6831-6864, 1997.

Hartley, W. S., Hobbs, P. V., Ross, J. L., Russell, P. B., and Livingston, J. M.: Properties of aerosols aloft relevant to direct aerosol radiative forcing off the mid-Atlantic coast of the United States, J. Geophys. Res., 105, 9859-9885, 2000.

Haywood, J. M., Francis, P., Dubovik, O., Glew, M., and Holben, B.: Comparison of aerosol size distributions, radiative properties, and optical depths determined by aircraft observations and Sun photometers during SAFARI 2000, J. Geophys. Res., 108, 8471, doi:10.1029/2002JD002250, 2003.

Haywood, J. M. and Ramaswamy, V.: Global sensitivity studies of the direct radiative forcing due to anthropogenic sulfate and black carbon aerosols, J. Geophys. Res., 103, 6043-6058, 1998.

Haywood, J. M. and Shine, K. P.: The effect of anthropogenic sulfate and soot aerosol on the clear sky planetary radiation budget, Geophys. Res. Lett., 22, 603-606, 1995.

Hinds, W. C., Aerosol Technology: Properties, behavior and measurement of airborne particles, John Wiley and Sons, New York, 1982.

Holben, B. N., Eck, T. F., Slutsker, I., Tanre, D., Buis, J. P., Setzer, A., Vermote, E., Reagan, J. A., Kaufman, Y. J., Nakajima, T., Lavenu, F., Jankowiak, I., and Smirnov, A.: AERONET - A federated instrument network and data archive for aerosol characterization, Remote Sens. Environ., 66, 1-16, 1998.

Holben, B. N., Eck, T. F., Slutsker, I., Smirnov, A., Sinyuk, A., Schafer, J., Giles, D., and Dubovik O.: AERONET's Version 2.0 quality assurance criteria, http://aeronet.gsfc.nasa.gov/new_web/ Documents/AERONETcriteria_final1.pdf (last access: 10 March 2014), 2006

Huffman, J. A., Docherty, K. S., Mohr, C., Cubison, M. J., U1brich, I. M., Ziemann, P. J., Onasch, T. B., and Jiminez, J. L.: Chemically-resolved volatility measurements of organic aerosol from different sources, Environ. Sci. Technol., 43, 5351-5357, 2009

Jeong, M.-J. and Li, Z.: Separating real and apparent effects of cloud, humidity, and dynamics on aerosol optical thickness near cloud edges, J. Geophys. Res., 115, D00K3, doi:10.1029/2009JD013547, 2010.

Johnson, B. T., Christopher, S., Haywood, J. M., Osborne, S. R., McFarlane, S., Hsu, C., Salustro, C., and Kahn, R.: Measurements of aerosol properties from aircraft, satellite and groundbased remote sensing: A case-study from the Dust and Biomassburning Experiment (DABEX), Q. J. R. Meteorol. Soc., 135, 922-934, 2009.

Johnson, B. T. and Osborne, S. R.: Physical and optical properties of mineral dust aerosol measured by aircraft during the GERBILS campaign, Q. J. R. Meteorol. Soc., 137, 1117-1130, 2011.

Kanaya, Y., Taketani, F., Komazaki, Y., Liu, X., Kondo, Y., Sahu, L., Irie, H., and Takashima, H.: Comparison of Black Carbon Mass Concentrations Observed by Multi-Angle Absorption Photometer (MAAP) and Continuous Soot-Monitoring System (COSMOS) on Fukue Island and in Tokyo, Japan, Aerosol Sci. Tech., 7, 1-10, doi:10.1080/02786826.2012.716551, 2013.

Kasten, F.: Visibility forecast in the phase of pre-condensation, Tellus, 21, 631-635, 1969.

Kelektsoglou, K., Rapsomanikis, S., Karageorgos, E. T., and Kosmadakis, I.: Optical properties of aerosol over a Southern European urban environment, Int. J. Remote Sens., 33, 1214-1233, 2012.

Kinne, S., Schulz, M., Textor, C., Guibert, S., Balkanski, Y., Bauer, S. E., Berntsen, T., Berglen, T. F., Boucher, O., Chin, M., Collins, W., Dentener, F., Diehl, T., Easter, R., Feichter, J., Fillmore, D., Ghan, S., Ginoux, P., Gong, S., Grini, A., Hendricks, J., Herzog, M., Horowitz, L., Isaksen, I., Iversen, T., Kirkevåg, A., Kloster, S., Koch, D., Kristjansson, J. E., Krol, M., Lauer, A., Lamarque, J. F., Lesins, G., Liu, X., Lohmann, U., Montanaro, V., Myhre, G., Penner, J., Pitari, G., Reddy, S., Seland, O., Stier, P., Takemura, T., and Tie, X.: An AeroCom initial assessment - optical properties in aerosol component modules of global models, Atmos. Chem. Phys., 6, 1815-1834, doi:10.5194/acp-6-1815-2006, 2006.

Koch, D., Schulz, M., Kinne, S., McNaughton, C., Spackman, J. R., Balkanski, Y., Bauer, S., Berntsen, T., Bond, T. C., Boucher, O., Chin, M., Clarke, A., De Luca, N., Dentener, F., Diehl, T., Dubovik, O., Easter, R., Fahey, D. W., Feichter, J., Fillmore, D., Freitag, S., Ghan, S., Ginoux, P., Gong, S., Horowitz, L., Iversen, T., Kirkevåg, A., Klimont, Z., Kondo, Y., Krol, M., Liu, X., Miller, R., Montanaro, V., Moteki, N., Myhre, G., Penner, J. E., Perlwitz, J., Pitari, G., Reddy, S., Sahu, L., Sakamoto, H., Schuster, G., Schwarz, J. P., Seland, Ø., Stier, P., Takegawa, N., Takemura, T., Textor, C., van Aardenne, J. A., and Zhao, Y.: Eval- 
uation of black carbon estimations in global aerosol models, Atmos. Chem. Phys., 9, 9001-9026, doi:10.5194/acp-9-9001-2009, 2009.

Kotchenruther, R. A., Hobbs, P. V., and Hegg, D. A.: Humidification factors for atmospheric aerosols off the mid-Atlantic coast of the United States, J. Geophys. Res., 104, 2239-2251, 1999.

Lacagnina, C., Hasekamp, O. P., Bian, H., Curci, G., Myhre, G., van Noije, T, Schulz, M., Skeie, R. B., Takemura, T., and Zhang, K.: Aerosol single-scattering albedo over the global oceans: Comparing PARASOL retrievals with AERONET, OMI, and AeroCom models estimates, J. Geophys. Res.-Atmos., 120, 98149836, doi:10.1002/2015JD023501, 2015.

Lack, D. A., Quinn, P. K., Massoli, P., Bates, T. S., Coffman, D., Covert, D. S., Sierau, B., Tucker, S., Baynard, T., Lovejoy, E., Murphy, D. M., and Ravishankara, A. R.: Relative humidity dependence of light absorption by mineral dust after long-range atmospheric transport from the Sahara, Geophys. Res. Lett., 36, L24805, doi:10.1029/2009GL041002, 2009.

Lack, D. A., Cappa, C. D., Covert, D. S., Baynard, T., Massoli, P., Sierau, B., Bates, T. S., Quinn, P. K., Lovejoy, E. R., and Ravishankara, A. R.: Bias in Filter-Based Aerosol Light Absorption Measurements Due to Organic Aerosol Loading: Evidence from Ambient Measurement, Aerosol Sci. Tech., 42, 1033-1041, 2008.

Lack, D. A., Richardson, M. S., Law, D., Langridge, J. M., Cappa, C. D., McLaughlin, R. J., and Murphy, D. M.: Aircraft Instrument for Comprehensive Characterization of Aerosol Optical Properties, Part 2: Black and Brown Carbon Absorption and Absorption Enhancement Measured with Photo Acoustic Spectroscopy, Aerosol Sci. Tech., 46, 555568,doi:10.1080/02786826.2011.645955, 2012.

Leahy, L. V., Anderson, T. L., Eck, T. F., and Bergstrom, R. W.: A synthesis of single scattering albedo of biomass burning aerosol over southern Africa during SAFARI 2000, Geophys. Res. Lett., 34, L12814, doi:10.1029/2007GL029697, 2007.

Li, S., Kahn, R., Chin, M., Garay, M. J., and Liu, Y.: Improving satellite-retrieved aerosol microphysical properties using GOCART data, Atmos. Meas. Tech., 8, 1157-1171, doi:10.5194/amt-8-1157-2015, 2015.

Ma, X. and Yu, F.: Seasonal variability of aerosol vertical profiles over east US and west Europe: GEOS-Chem/APM simulation and comparison with CALIPSO observations, Atmos. Res., 140/141, 28-37, doi:10.1016/j.atmosres.2014.01.001, 2014.

Magi, B. I., Hobbs, P. V., Kirchstetter, T. W., Novakov, T., Hegg, D. A., Gao, S., Redemann, J., and Schmid, B.: Aerosol Properties and Chemical Apportionment of Aerosol Optical Depth at Locations off the US East Coast in July and August 2001, J. Atmos. Sci., 62, 919-933, 2005.

Magi, B. I., Hobbs, P. V., Schmid, B., and Redemann, J.: Vertical profiles of light scattering, light absorption and single scattering albedo during the dry biomass burning season in southern Africa and comparisons of in-situ and remote sensing measurements of aerosol optical depths, J. Geophys. Res., 108, 8504, doi:10.1029/2002JD00236, 2003.

Mallet, M., Dubovik, O., Nabat, P., Dulac, F., Kahn, R., Sciare, J., Paronis, D., and Léon, J. F.: Absorption properties of Mediterranean aerosols obtained from multi-year ground-based remote sensing observations, Atmos. Chem. Phys., 13, 9195-9210, doi:10.5194/acp-13-9195-2013, 2013.
Mallet, M., Van Dingenen, R., Roger, J. C., Despiau, S., and Cachier, H.: In situ airborne measurements of aerosol optical properties during photochemical pollution events, J. Geophys. Res., 110, D03205, doi:10.1029/2004JD005139, 2005.

Mallet, M., Pont, V., Liousse, C., Gomes, L., Pelon, J., Osborne, S., Haywood, J., Roger, J. C., Dubuisson, P., Mariscal, A., Thouret, V., and Gouloub, P.: Aerosol direct radiative forcing of Djougou (northern Benin) during the African Monsoon Multidisciplinary, Analysis dry season experiment (special observation period -0), J. Geophys. Res., 113, D00C01, doi10.29/2007JD009419, 2008.

Malm, W. C., Sisler, J. F., Huffman, D., Eldred, R. A., and Cahill, T. A.: Spatial and seasonal trends in particle concentration and optical extinction in the United States, J. Geophys. Res., 99, 13471370, 1994.

McConnell, C. L., Highwood, E. J., Coe, H., Formenti, P., Anderson, B., Osborne, S., Nava, S. Desboeufs, K., Chen, G., and Harrison, M. A. J.: Seasonal variations of the physical and optical characteristics of Saharan dust: Results from the Dust Outflow and Deposition to the Ocean (DODO) experiment, J. Geophys. Res., 113, D14S05, doi:10.1029/2007JD009606, 2008.

McMeeking, G. R., Fortner, E., Onasch, T. B., Taylor, J. W., Flynn, M., Coe, H., and Kreidenweis, S. M.: Impacts of nonrefractory material on light absorption by aerosols emitted from biomass burning, J. Geophys. Res.-Atmos., 119, 12272-12286, doi:10.1002/2014JD021750, 2014.

Mendes, L., Eleftheriadis, K., and Biskos, G.: Performance comparison of two thermal denuders in volatility tandem DMA measurements, J. Aerosol Sci., 92, 38-52, 2016.

Müller, D., Lee, K.-H., Gasteiger, J., Tesche, M., Weinzierl, B., Kandler, K., Muller, T., Toledano, C., Otto, S., Althausen, D., and Ansmann, A.: Comparison of optical and microphysical properties of pure Saharan mineral dust observed with AERONET Sun photometer, Raman lidar, and in situ instruments during SAMUM 2006, J. Geophys. Res., 117, D07211, doi:10.1029/2011JD016825, 2012.

Müller, T., Henzing, J. S., de Leeuw, G., Wiedensohler, A., Alastuey, A., Angelov, H., Bizjak, M., Collaud Coen, M., Engström, J. E., Gruening, C., Hillamo, R., Hoffer, A., Imre, K., Ivanow, P., Jennings, G., Sun, J. Y., Kalivitis, N., Karlsson, H., Komppula, M., Laj, P., Li, S.-M., Lunder, C., Marinoni, A., Martins dos Santos, S., Moerman, M., Nowak, A., Ogren, J. A., Petzold, A., Pichon, J. M., Rodriquez, S., Sharma, S., Sheridan, P. J., Teinilä, K., Tuch, T., Viana, M., Virkkula, A., Weingartner, E., Wilhelm, R., and Wang, Y. Q.: Characterization and intercomparison of aerosol absorption photometers: result of two intercomparison workshops, Atmos. Meas. Tech., 4, 245-268, doi:10.5194/amt-4-245-2011, 2011.

Myhre, G., Samset, B. H., Schulz, M., Balkanski, Y., Bauer, S., Berntsen, T. K., Bian, H., Bellouin, N., Chin, M., Diehl, T., Easter, R. C., Feichter, J., Ghan, S. J., Hauglustaine, D., Iversen, T., Kinne, S., Kirkevåg, A., Lamarque, J.-F., Lin, G., Liu, X., Lund, M. T., Luo, G., Ma, X., van Noije, T., Penner, J. E., Rasch, P. J., Ruiz, A., Seland, Ø., Skeie, R. B., Stier, P., Takemura, T., Tsigaridis, K., Wang, P., Wang, Z., Xu, L., Yu, H., Yu, F., Yoon, J.-H., Zhang, K., Zhang, H., and Zhou, C.: Radiative forcing of the direct aerosol effect from AeroCom Phase II simulations, Atmos. Chem. Phys., 13, 1853-1877, doi:10.5194/acp-13-18532013, 2013. 
Nessler, R., Weingartner, E., and Baltensperger, U.: Effect of humidity on aerosol light absorption and its implications for extinction and the single scattering albedo illustrated for a site in the lower free troposphere, J. Aerosol Sci., 36, 958-972, 2005.

Ogren, J. A.: Comment on "Calibration and Intercomparison of Filter-Based Measurements of Visible Light Absorption by Aerosols", Aerosol Sci. Tech., 44, 589-591, doi:10.1080/02786826.2010.482111, 2010.

O’Neill, N. T., Eck, T. F., Smirnov, A., Holben, B. N., and Thulasiraman, S.: Spectral discrimination of coarse and fine mode optical depth, J. Geophys. Res., 108, 4559-4573, 2003.

Osborne, S. R., Johnson, B. T., Haywood, J. M., Baran, A. J., Harrison, M. A. J., and McConnell, C. L.: Physical and optical properties of mineral dust aerosol during the Dust and Biomass-burning Experiment, J. Geophys. Res., 113, D00C03, doi:10.1029/2007JD009551, 2008.

Pan, X., Chin, M., Gautam, R., Bian, H., Kim, D., Colarco, P. R., Diehl, T. L., Takemura, T., Pozzoli, L., Tsigaridis, K., Bauer, S., and Bellouin, N.: A multi-model evaluation of aerosols over South Asia: common problems and possible causes, Atmos. Chem. Phys., 15, 5903-5928, doi:10.5194/acp-15-5903-2015, 2015.

Parworth, C., Fast, J., Meib, F., Shipper, T., Sivaraman, C., Tilp, A., Watson, T., and Zhang, Q.: Long-term measurements of submicrometer aerosol chemistry at the Southern Great Plains (SGP) using an Aerosol Chemical Speciation Monitor (ACSM), Atmos. Environ., 106, 43-55, 2015.

Petzold, A., Ogren, J. A., Fiebig, M., Laj, P., Li, S.-M., Baltensperger, U., Holzer-Popp, T., Kinne, S., Pappalardo, G., Sugimoto, N., Wehrli, C., Wiedensohler, A., and Zhang, X.-Y.: Recommendations for reporting "black carbon" measurements, Atmos. Chem. Phys., 13, 8365-8379, doi:10.5194/acp-13-83652013, 2013.

Quinn, P. K., Bates, T. S., Baynard, T., Clarke, A. D., Onasch, T. B., Wang, W., Rood, M. J., Andrews, E., Allan, J., Carrico, C. M., Coffman, D., and Worsnop, D.: Impact of particulate organic matter on the relative humidity dependence of light scattering: A simplified parameterization, Geophys. Res. Lett., 32, L22809, doi:10.1029/2005GL024322, 2005.

Ramanathan, V. and Carmichael, G.: Global and regional climate changes due to black carbon, Nat. Geosci., 1, 221-227, 2008.

Reddy, M. S., Boucher, O. Bellouin, N., Schulz, M., Balkanski, Y., Dufresne, J. L., and Pham, M.: Estimates of global multicomponent aerosol optical depth and direct radiative perturbation in the Laboratoire de Meteorologie Dynamique general circulation model, J. Geophys. Res., 110, D10S16, doi:10.1029/2004jd004757, 2005.

Redemann, J., Russell, P. B., and Hamill, P.: Dependence of aerosol light absorption and single scattering albedo on ambient relative humidity for sulfate aerosols with black carbon cores, J. Geophys. Res., 106, 27485-27495, 2001.

Reid, J. S., Hobbs, P. V., Liousse, C., Vanderlei Martins, J., Weiss, R. E., and Eck, T. F.: Comparisons of techniques for measuring shortwave absorption and black carbon content of aerosols from biomass burning in Brazil, J. Geophys. Res., 103, 32031-32040, 1998.

Samset, B. H., Myhre, G., Schulz, M., Balkanski, Y., Bauer, S., Berntsen, T. K., Bian, H., Bellouin, N., Diehl, T., Easter, R. C., Ghan, S. J., Iversen, T., Kinne, S., Kirkevåg, A., Lamarque, J.-
F., Lin, G., Liu, X., Penner, J. E., Seland, Ø., Skeie, R. B., Stier, P., Takemura, T., Tsigaridis, K., and Zhang, K.: Black carbon vertical profiles strongly affect its radiative forcing uncertainty, Atmos. Chem. Phys., 13, 2423-2434, doi:10.5194/acp-13-24232013, 2013.

Sato, M., Hansen, J., Kock, D., Lacis, A., Ruedy, R., Dubovik, O., Holben, B., Chin, M., and Novakov, T.: Global atmospheric black carbon inferred from AERONET, PNAS, 100, 6319-6324, 2003.

Schafer, J. S., Eck, T. F., Holben, B. N., Thornhill, K. L., Anderson, B. E., Sinyuk, A., Giles, D. M., Winstead, E. L., Ziemba, L. D., Beyersdorf, A. J., Kenny, P. R., Smirnov, A., and Slutsker, I.: Intercomparison of aerosol single-scattering albedo derived from AERONET surface radiometers and LARGE in situ aircraft profiles during the 2011 DRAGON-MD and DISCOVER-AQ experiments, J. Geophys. Res., 119, 74397452, doi:10.1002/2013JD021166, 2014.

Schmid, B., Flynn, C. J., Newsom, R. K., Turner, D. D., Ferrare, R. A., Clayton, M. F., Andrews, E., Ogren, J. A., Johnson, R. R., Russell, P. B., Gore, W. J., and Dominguez, R.: Validation of aerosol extinction and water vapor profiles from routine Atmospheric Radiation Measurement Program Climate Research Facility measurements, J. Geophys. Res., 114, D22207, doi:10.1029/2009JD012682, 2009.

Schutgens, N. A. J., Partridge, D. G., and Stier, P.: The importance of temporal collocation for the evaluation of aerosol models with observations, Atmos. Chem. Phys., 16, 1065-1079, doi:10.5194/acp-16-1065-2016, 2016.

Schwarz, J. P., Spackman, J. R., Fahey, D. W., Gao, R. W., Lohmann, U., Stier, P., Watts, L. A., Thomson, D. S., Lack, D. A., Pfister, L., Mahoney, M. J., Baumgardner, D., Wilson, J. C., and Reeves, J. M.: Coatings and their enhancement of black carbon light absorption in the tropical atmosphere, J. Geophys. Res., 113, D03203, doi:10.1029/2007JD009042, 2008.

Schwarz, J. P., Spackman, J. R., Gao, R. S., Watts, L. A., Stier, P., Schulz, M., Davis, S. M., Wofsy, S. C., and Fahey, D. W.: Global-scale black carbon profiles observed in the remote atmosphere and compared to models, Geophys. Res. Lett., 27, L18812, doi:10.1029/2010GL044372, 2010.

Sharma, S., Ishizawa, M., Chan, D., Lavoue, D., Andrews, E., Eleftheriadis, K., and Maksyutov, S.: 16-year simulation of Arctic black carbon: transport, source contribution, and sensitivity analysis on deposition, J. Geophys. Res., 118, 1-22, doi:10.1029/2012JD017774, 2013.

Sheridan, P. J., Andrews, E., Ogren, J. A., Tackett, J. L., and Winker, D. M.: Vertical profiles of aerosol optical properties over central Illinois and comparison with surface and satellite measurements, Atmos. Chem. Phys., 12, 11695-11721, doi:10.5194/acp12-11695-2012, 2012.

Sheridan, P. J., Arnott, W. P., Ogren, J. A., Andrews, E., Atkinson, D. B., Covert, D. S., Moosmüller, H., Petzold, A., Schmid, B. Strawa, A. W., Varma, R., and Virkkula, A.: The Reno Aerosol Optics Study: An Evaluation of Aerosol Absorption Measurement Methods, Aerosol Sci. Tech., 39, 1-16, 2005.

Sheridan, P. J., Delene, D. J., and Ogren, J. A.: Four years of continuous surface aerosol measurements from the Department of Energy's Atmospheric Radiation Measurement Program Southern Great Plains Cloud and Radiation Testbed site, J. Geophys. Res., 106, 20735-20747, 2001. 
Sheridan, P. J., Jefferson, A., and Ogren, J. A.: Spatial variability of submicrometer aerosol radiative properties over the Indian Ocean during INDOEX, J. Geophys. Res., 107, D198011, doi:10.1029/2000JD000166, 2002.

Sherman, J. P., Sheridan, P. J., Ogren, J. A., Andrews, E., Hageman, D., Schmeisser, L., Jefferson, A., and Sharma, S.: A multi-year study of lower tropospheric aerosol variability and systematic relationships from four North American regions, Atmos. Chem. Phys., 15, 12487-12517, doi:10.5194/acp-1512487-2015, 2015.

Shinozuka, Y., Redemann, J., Livingston, J. M., Russell, P. B., Clarke, A. D., Howell, S. G., Freitag, S., O’Neill, N. T., Reid, E. A., Johnson, R., Ramachandran, S., McNaughton, C. S., Kapustin, V. N., Brekhovskikh, V., Holben, B. N., and McArthur, L. J. B.: Airborne observation of aerosol optical depth during ARCTAS: vertical profiles, inter-comparison and fine-mode fraction, Atmos. Chem. Phys., 11, 3673-3688, 2011.

Sinha, P., Hobbs, P. V., Yokelson, R. J., Bertschi, I. T., Blake, D. R., Simpson, I., Gao, S., Kirchstetter, T. W., and Novakov, T.: Emissions of trace gases and particles from savanna fires in southern Africa, J. Geophys. Res., 108, 8487, doi:10.1029/2002JD002325, 2003.

Sinha, P. R., Kondo, Y., Koike, M., Ogren, J. A., Jefferson, A., Barrett, T. E., Sheesley, R. J., Ohata, S., Moteki, N., Coe, H., Liu, D., Irwin, M., Tunved, P., Quinn, P. K., and Zhao, Y.: Evaluation of ground-based black carbon measurements by filter-based photometers at two Arctic sites, in review, J. Geophys. Res., in press, 2017.

Skeie, R. B., Berntsen, T., Myhre, G., Pedersen, C. A., Ström, J., Gerland, S., and Ogren, J. A.: Black carbon in the atmosphere and snow, from pre-industrial times until present, Atmos. Chem. Phys., 11, 6809-6836, doi:10.5194/acp-11-6809-2011, 2011.

Smirnov, A., Holben, B. N., Eck, T. F., Dubovik, O., and Slutsker, I.: Cloud screening and quality control algorithms for the AERONET database, Remote Sens. Environ., 73, 337-349, 2000 .
Subramanian, R., Roden, C. A., Boparai, P., and Bond, T. C.: Yellow beads and missing particles: Trouble ahead for filterbased absorption measurements, Aerosol Sci. Tech., 41, 630637, doi:10.1080/02786820701344589, 2007.

Taubman, B. F., Hains, J. C., Thompson, A. M., Marufu, L. T., Doddridge, B. G., Stehr, J. W., Piety, C. A., and Dickerson, R. R.: Aircraft vertical profiles of trace gas and aerosol pollution over the mid-Atlantic United States: Statistics and meteorological cluster analysis, J. Geophys. Res., 111, D10S07, doi:10.1029/2005JD006196, 2006.

Turner, D. D., Ferrare, R. A., Brasseur, L. A.: Average Aerosol Extinction and Water Vapor Profiles over the Southern Great Plains, Geophys. Res. Lett., 28, 4441-4444, 2001.

Vaden, T. D., Imre, D., Baranek, J., Shrivastava, M., Zelenyuk, A., and Finlayson-Pitts, B. J.: Evaporation kinetics and phase of laboratory and ambient secondary organic aerosol, PNAS, 108, 2190-2195, 2011.

Virkkula, A.: Correction of the Calibration of the 3-wavelength Particle Soot Absorption Photometer (3 PSAP), Aerosol Sci. Tech., 44, 706-712, 2010.

Wang, R., Balkanski, Y., Boucher, O., Ciais, P., Schuster, G. L., Chevallier, F., Samset, B. H., Liu, J., Piao, S., Valari, M., and Tao, S.: Estimation of global black carbon direct radiative forcing and its uncertainty constrained by observations, J. Geophys. Res.Atmos., 121, 5948-5971, doi:10.1002/2015JD024326, 2016.

Wang, X., Heald, C. L., Ridley, D. A., Schwarz, J. P., Spackman, J. R., Perring, A. E., Coe, H., Liu, D., and Clarke, A. D.: Exploiting simultaneous observational constraints on mass and absorption to estimate the global direct radiative forcing of black carbon and brown carbon, Atmos. Chem. Phys., 14, 10989-11010, doi:10.5194/acp-14-10989-2014, 2014.

Yu, F., Chin, M., Winker, D. M., Omar, A. H., Liu, Z., Kittaka, C., and Diehl, T.: Global view of aerosol vertical distributions from CALIPSO lidar measurements and GOCART simulations: Regional and seasonal variations, J. Geophys. Res., 115, D00H30, doi:10.1029/2009JD013364, 2010. 